\title{
WestVirginiaUniversity
}

THE RESEARCH REPOSITORY @ WVU

Graduate Theses, Dissertations, and Problem Reports

2019

\section{A Video Decision Aid to Influence Advance Care Planning}

Angela Petry

West Virginia University, apetry261@yahoo.com

Follow this and additional works at: https://researchrepository.wvu.edu/etd

Part of the Family Practice Nursing Commons, and the Geriatric Nursing Commons

\section{Recommended Citation}

Petry, Angela, "A Video Decision Aid to Influence Advance Care Planning" (2019). Graduate Theses, Dissertations, and Problem Reports. 4103.

https://researchrepository.wvu.edu/etd/4103

This Problem/Project Report is protected by copyright and/or related rights. It has been brought to you by the The Research Repository @WVU with permission from the rights-holder(s). You are free to use this Problem/Project Report in any way that is permitted by the copyright and related rights legislation that applies to your use. For other uses you must obtain permission from the rights-holder(s) directly, unless additional rights are indicated by a Creative Commons license in the record and/ or on the work itself. This Problem/Project Report has been accepted for inclusion in WVU Graduate Theses, Dissertations, and Problem Reports collection by an authorized administrator of The Research Repository @ WVU. For more information, please contact researchrepository@mail.wvu.edu. 


\section{WestVirginiaUniversity \\ THE RESEARCH REPOSITORY @ WVU}

Graduate Theses, Dissertations, and Problem Reports

2019

\section{A Video Decision Aid to Influence Advance Care Planning}

Angela Petry

Lori A. Constantine

Katharine Joy Buck

Follow this and additional works at: https://researchrepository.wvu.edu/etd 


\section{A Video Decision Aid to Influence Advance Care Planning Angela Dawn Petry, BSN, MSN \\ Project/Problem Report submitted to the School of Nursing at \\ West Virginia University \\ in partial fulfillment of the requirements for the degree of \\ Doctor of Nursing Practice}

Lori A. Constantine DNP, APRN, FNP-BC, Chair

Katharine Joy Buck, PhD, APRN

Constance Beckom, MD

\section{Department of Nursing}

Morgantown, WV

2019

Keywords: advance care planning, nurse practitioner, end of life, video support Copyright 2019, Angela Dawn Petry 


\author{
ABSTRACT \\ A Video Decision Aid to Support Advance Care Planning \\ Angela Dawn Petry
}

The best mechanism to achieve successful advance care planning has yet to be identified. A randomized, controlled, experimental study was performed with a sample of 54 men and women who met inclusion criteria and were randomized into the intervention versus the control group in an outpatient clinical setting in rural West Virginia (WV) from December 2018 to March 2019. Participant mean age was 72.4 years. For those who chose to participate $(n=42)$, the intervention group received the usual standard of care, which was a face to face advance care planning (ACP) discussion with the new intervention of a video decision aid in preparation to complete advance directives (AD) or have Physician Orders for Scope of Treatment (POST) forms completed by the healthcare provider. Those in the control group who agreed to participate received only the standard of care. Overall, $73.8 \%(n=31)$ of the total participants completed AD as a result of any ACP intervention. Participants who received the video intervention in addition to the standard of care completed more advance directives than those who only received the usual standard of care (88\% vs 63\%). The video decision aid should be an additive component to ACP interactions to enrich the standard verbal counseling. Additionally, incorporating evidenced-based guidelines connects ethical and regulatory components to ACP interactions. Health care organizational culture should support an environment that standardizes end of life (EOL) conversations in every practice setting. Further research should be done to determine the most effective approach in delivery of ACP. 


\section{Table of Contents}

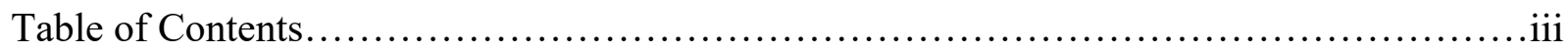

Acknowledgements..........................................................

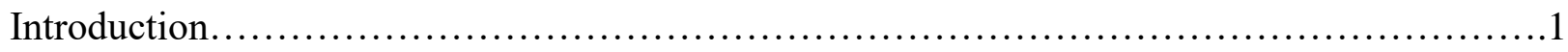

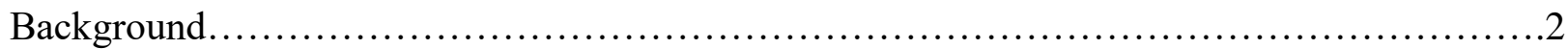

Problem Statement.........................................................

Purpose of the Project.........................................................

Significance of the Project...............................................4

Literature Review and Synthesis.......................................................

Methods................................................................4

Literature Review....................................................... 5

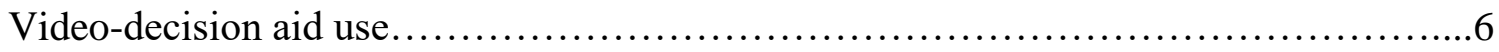

Nurse Practitioner's Role in the Advance Care Planning Process....................

Advance Care Planning Impact on Outcomes..................................15

Expert Opinion.........................................................16

Synthesis............................................................ 17

Evidenced Based Best Practice.................................................. 17

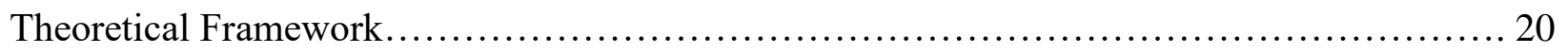

Project Description..............................................................22

Institutional Review Board................................................ 22

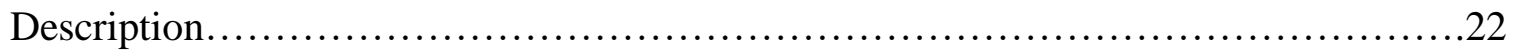

Video Decision Aid.........................................................23

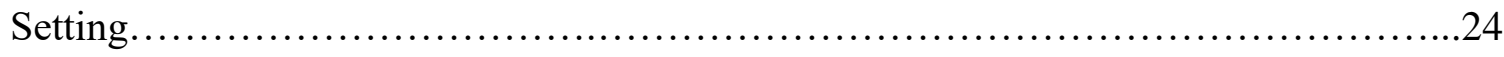


Running Head: A VIDEO DECISION AID TO INFLUENCE ADVANCE CARE PLANNING

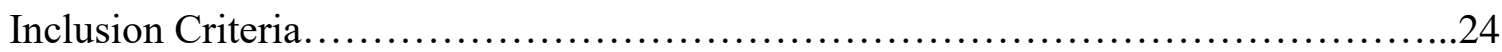

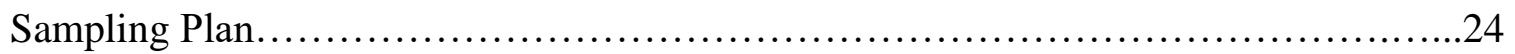

Recruitment and Enrollment...............................................24

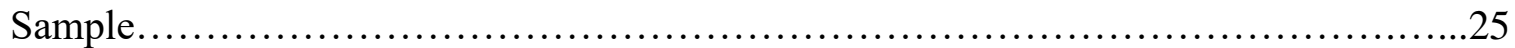

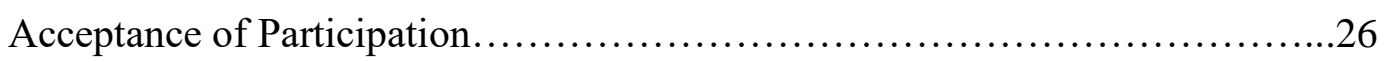

APRN Preparation.......................................................27

Staff Education and Communication...........................................27

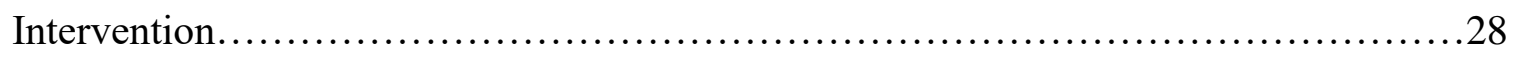

Data Collection........................................................... 28

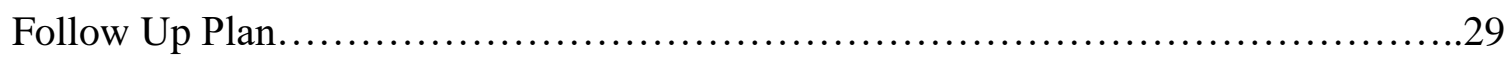

Application of Theoretical Framework.........................................29

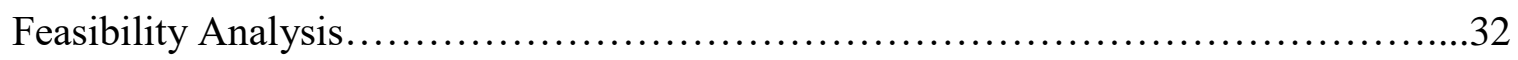

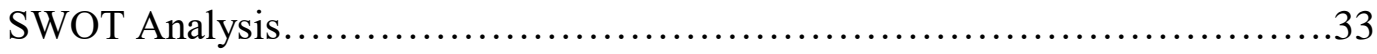

Impact Analysis.................................................. 34

Sustainability .................................................. 35

Project Resources.......................................................... 36

Committee.............................................................

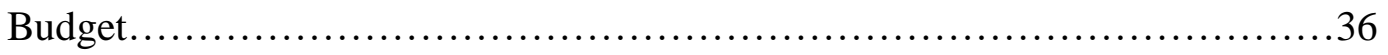

Costs and Benefit................................................ 37

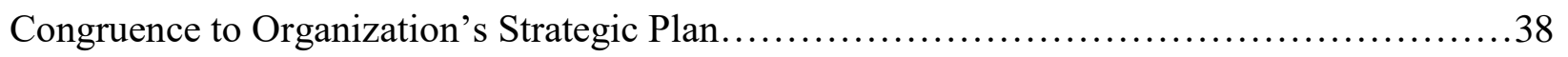

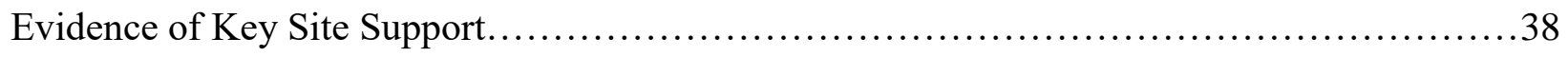

Project Goals and Objectives........................................................

Future Goals........................................................... 40 
Running Head: A VIDEO DECISION AID TO INFLUENCE ADVANCE CARE PLANNING

Outcome Evaluation Plan.......................................................41

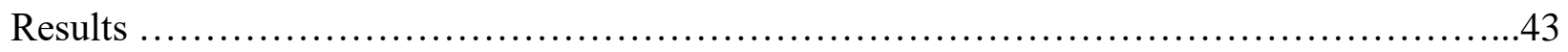

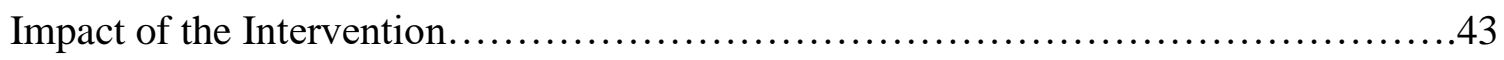

Discussion and Recommendations...................................................4

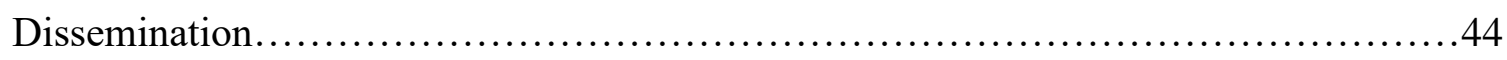

Challenges and Limitations.................................................... 44

Barrier to Recruitment.................................................. 45

Proper Documentation......................................................... 45

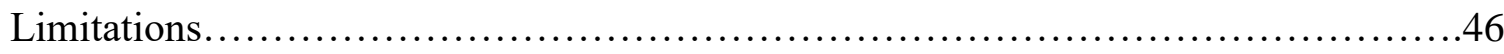

Recommendations............................................................. 47

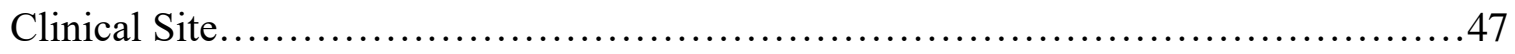

Implementation in Other Clinical Settings.......................................49

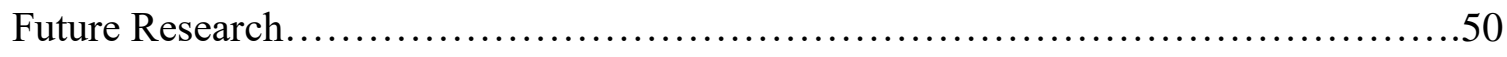

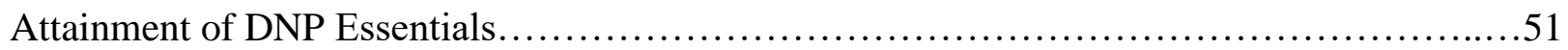

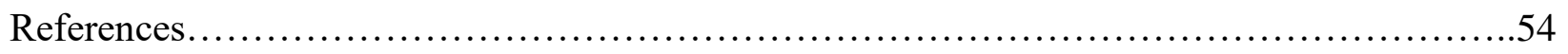


Running Head: A VIDEO DECISION AID TO INFLUENCE ADVANCE CARE PLANNING

Figures, Appendices, and Table Index

Figure 1: Kurt Lewin's Change Management Theory Model..............................58

Figure 2: Force Field Analysis Model............................................59

Figure 3: Evidence of Key Site Support........................................ 60

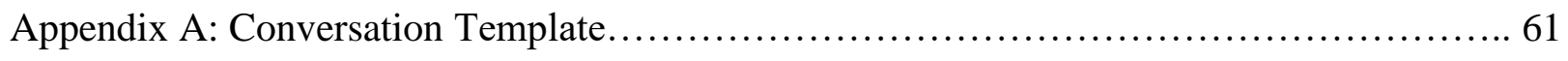

Appendix B: Data Collection Tool................................................62

Appendix C: Project Budget Proposal............................................63

Appendix D: Mission and Vision Link with Project Goals.............................64

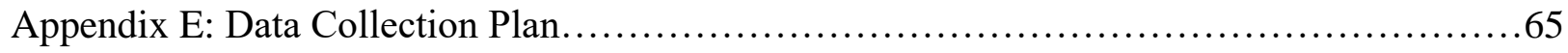

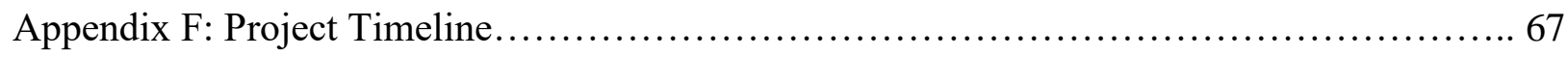

Table 1: Participation Refusal Chart.............................................68

Table 2: Advance Directive Completion by Any Intervention..............................69

Table 3: Advance Directive Completion by Intervention Type...........................70 
Running Head: A VIDEO DECISION AID TO INFLUENCE ADVANCE CARE PLANNING

\section{Acknowledgment}

I would like to begin by expressing my sincere appreciation to Dr. Lori Constantine, committee chair, for your dedication, expertise, and leadership demonstrated throughout this academic journey. I would also like to offer my special thanks to Dr. Joy Buck, committee member, for your invaluable source of knowledge, advice, and feedback that richly enhanced this research experience. You both were inspirational in helping me accomplish the completion of this project. I value your professional guidance, expertise and comradery.

To Dr. Constance Beckom, committee member and content expert, it has been a pleasure to have your friendship, inspiration, and encouragement throughout the past few years. You believed in me even when I doubted my own abilities. You pressed me to think bigger and reach higher than I believed I could and to find the determination to overcome the many challenges faced along the way. Because of that, I have cultivated greater personal and professional qualities. Most of all, I gained a friend and esteemed colleague.

To my family and friends, my achievements would not be possible without the love, support, and patience you've shown throughout my academic journey. You are the reason I strive to be the best I can be. You were always my biggest fans- in good times and bad- my shoulder to cry on- my sounding board- but most importantly my source of strength during the most daunting times of this journey. For that, I offer my love and sincere gratitude. 
Running Head: A VIDEO DECISION AID TO INFLUENCE ADVANCE CARE PLANNING

\section{Introduction}

In the United States (US), only one-third of the adult population has completed AD or medical orders for EOL care (Rao, Anderson, Feng-Cheng, \& Laux, 2014). In the primary care setting the prevalence of ACP discussions are low. Fewer than $50 \%$ of patients with end stage illness have engaged in ACP with their primary healthcare provider. (Respecting Choices®, 2018). As a result, patient preferences for EOL care are often unknown prior to an emergent, medical crisis and are unavailable to the treating provider at least $25 \%$ of the time. (Rietze, Heale, Hill, \& Roles, 2016). Frequently, it is not until a patient is faced with a life-threatening event when these discussions occur. In these circumstances patients are often cognitively impaired and unable to make care-related decisions or even verbalize their wishes. As a result, the burden is placed on the healthcare provider and family to determine what level of treatment the patient may desire.

According to the Center for Disease Control's Healthy Aging (n.d.) report, $90 \%$ of healthcare providers and patients support the concept for ACP, yet only approximately $20 \%$ of the public have engaged in such conversations with a healthcare provider. Many studies have shown that open and honest discussion of ACP options can significantly enable shared decisionmaking for EOL preferences (Splendor \& Grant, 2017). However, without documentation of ACP conversations, many patients who want to die in a home setting, may die in the hospital instead (Institute of Medicine, 2014).

One approach to increase the numbers of ACP conversations and subsequent documentation is to initiate ACP counseling in the primary care medical home (PCMH) setting while the individual is in a good state of health. ACP is an interactive process between patients and their healthcare provider aimed at making decisions about the care one would and would not 
Running Head: A VIDEO DECISION AID TO INFLUENCE ADVANCE CARE PLANNING want if seriously ill (National Hospice and Palliative Care Organization, 2017). Outputs of ACP include AD documents such as a Living will (LW) or medical power of attorney (MPOA) forms. In WV, these forms are in a combined LW/MPOA document. ACP may also result in POST and Do Not Resuscitate (DNR) orders. Shared decision-making regarding ACP has previously been through direct one-one conversations with the provider and the patient and their family or loved ones. Recent research suggests however, that a variety of communication techniques can promote well informed provider-patient dialogue, which supports ACP and documentation that reflects the patient's EOL goals and aligns with the patient's values.

\section{Background}

Issues around EOL treatment decisions have long been the focus of debate among providers, policy makers and the public. Starting in the 1960's the consumer rights movement brought awareness to the detriment of using life-sustaining treatment under certain circumstances. Later, the California Natural Death Act of 1976 was the first attempt to refocus EOL care using what is now known as a LW (US Department of Health and Human Services, 2008). Both state and federal courts, as well as Congress, have also helped lay the foundation for current approaches for EOL decision-making. Many well-publicized legal cases in the 1970s and 1980s, as well as state legislation, began to influence a legal model of ACP that focused on the protection of vulnerable individuals, such as those with permanent unconsciousness.

In the late 1980 s, it became evident that these laws alone were ineffective in preventing unwanted suffering by resuscitative means at EOL and determining what patients would and would not want at the end of their lives. Subsequently, Congress enacted the Patient SelfDetermination Act (PSDA) in 1990 to encourage competent adults to complete AD (US Department of Health and Human Services, 2008). The PSDA is a federal law with mandatory 
Running Head: A VIDEO DECISION AID TO INFLUENCE ADVANCE CARE PLANNING

compliance. Its aim is to ensure that competent adults have a right to make their own health care decisions, including accepting and rejecting medical care, through AD.

\section{Problem Statement}

Improvements in medical science and life-saving interventions have changed the nature of dying. People are living longer with multiple chronic disease. WV has the fourth highest median age and the second highest percentage of adults reporting fair to poor health status in the US. These individuals experience chronic illness that results in frailty, physical debility, and functional limitations (Institute of Medicine, 2014). Many of these individuals endure excessive and burdensome treatments during a life-threatening event, and do not survive. Furthermore, many of these deaths are foreseeable. Although WV has increased the rate of AD completion from $34 \%$ to $50 \%$, the highest in the nation, (WV Rural Health Association, 2013) the best mechanism to achieve successful ACP conversations with subsequent AD and medical order completion has yet to be determined.

\section{Purpose of the Project}

Innovative approaches, such as video-assisted intervention, can supplement difficult and sensitive EOL conversations. Consequently, patients tend to be more informed of EOL treatment options and can make decisions concordant with their values. The addition of a video decision aid can lead to identifying issues and eliciting thought-provoking questions that patients may not realize when engaging in verbal discussion alone (Jain et al., 2014). The purpose of this project is to investigate the utility of an ACP video decision aid in an outpatient primary care setting to determine its influence on the completion of ADs by elderly residents of WV. The video decision aid will be utilized to offer a visual component to ACP in addition to the standard of care ACP conversations only. 
Running Head: A VIDEO DECISION AID TO INFLUENCE ADVANCE CARE PLANNING

\section{Significance of the Project}

Currently, an estimated 34\% of Americans have completed an AD, (Rao et al.,2014) compared to $50 \%$ of WV residents who have completed AD (WV Rural Health Association, 2013). Advance Practice Registered Nurses (APRN) commonly engage patients with serious illness in EOL discussion; therefore, are in a strategic position to successfully provide ACP education in various clinical settings (Reitze et al., 2016). The use of a video decision aid by APRNs in ACP interactions is not well researched. However, because of initial research into the impact of using a video decision aid and the APRNs role in ACP, such a strategy for this provider group may lead to increased ACP with subsequent AD and EOL medical order completion.

\section{Literature Review and Synthesis}

\section{Methods}

To determine the impact of a video decision aid in ACP education and counseling, a systematic review was conducted. Eligible studies were identified from a search of the West Virginia University (WVU) Library database using Cumulative Index to Nursing and Allied Health Literature (CINAHL), Google Scholar, Medline, PubMed, and EbscoHost. Limitations placed on the search included human species, English language, population age greater than 55 years, and articles containing abstracts. There was not a limit set on publication year to ensure that all relevant scholarly articles were obtained. Key words containing Boolean operators and symbols that were included were "advance care planning", "end of life preferences", "advance directives AND elderly", "video support AND advance care planning”, and "nurse practitioners AND end-of-life". Initial results yielded 25 abstracts to review. 
Running Head: A VIDEO DECISION AID TO INFLUENCE ADVANCE CARE PLANNING

All 25 articles were reviewed for relevance to this study. A total of 14 articles were excluded once reviewed. Three articles were excluded for focusing on a specific disease at the EOL as it was believed the results would not be generalizable to the project's study participants. Five articles were eliminated as foreign studies that would not be generalizable to the American population's cultural EOL beliefs and norms. Four articles contained a sample population of adults aged 18 to 55, so it was excluded from this review due to this project's focus on the elderly. A younger population may have different perceptions regarding EOL care if they have not yet been faced with debilitating chronic disease or a life-threatening event. Lastly, two articles were eliminated as they focused on participants in long term care settings only. Overall, there were 11 studies relevant for review. These studies were identified as three systematic reviews (Jain et al., 2014 ; Kermel-Schiffman \& Werner, 2017; Weathers et al., 2016), one randomized controlled trial (El-Jawahri, et al., 2016), six quantitative single studies (Constantine et al., 2018; Dube et al., 2015; Rietze et al., 2016; Rao et al., 2014; Schlegal \& Shannon, 2000; Splendore \& Grant, 2017) and one expert opinion (Kates, 2017).

\section{Literature Review}

The 11 studies included for review were identified as three systematic reviews (Jain et al., 2014; Kermel-Schiffman \& Werner, 2017; Weathers et al., 2016), one randomized controlled trial (RCT) (El-Jawahri et al., 2016), six quantitative single studies (Constantine et al., 2018; Dube et al., 2015; Rietze et al., 2016; Rao et al., 2014; Schlegal \& Shannon, 2000; Splendore \& Grant, 2017) and one expert opinion (Kates, 2017). These studies can be grouped according to subject matter. Three studies (El- Jawahri et al., 2016; Jain et al., 2015; Kermel-Schiffman et al., 2017) looked at video aid use in advance care planning while all of the six quantitative studies

(Constantine et al., 2018; Dube et al., 2015; Rietze et al., 2016; Rao et al., 2014; Schlegal \& 
Running Head: A VIDEO DECISION AID TO INFLUENCE ADVANCE CARE PLANNING Shannon, 2000; Splendore \& Grant, 2017) evaluated the APRNs role in the ACP process. One study examined the impact of ACP planning on patient outcomes (Weathers et al., 2016). Lastly, one study provided expert opinion to educate APRNs with legislative updates and current resources intended to improve ACP conversations (Kates, 2017).

Video Decision Aid Use. Three studies (El- Jawahri et al., 2016; Jain et al., 2014; Kermel-Schiffman et al., 2017) investigated the utility of a video decision aid in ACP. KermelSchiffman \& Werner (2017) performed a systematic review of 37 quantitative and qualitative studies to examine the existing literature on knowledge regarding ACP. Participants of the studies varied but included nurses, healthcare clinicians, healthcare managers, social workers, and medical students. The studies investigated individual's subjective and objective knowledge of ACP. The results showed that approximately one half (45.9\%) of the sample had limited knowledge of ADs and were not aware of the PSDA. Nurses, especially, were familiar with the ACP process but were not aware of state laws and the legal aspects of counseling and documentation. Seven studies (18.9\%) reported moderate to high levels of knowledge regarding ACP in general, yet another seven studies (18.9\%) reported very low levels of knowledge. Six studies assessed interventions aimed at improving ACP knowledge using a videotape and interview in addition to supportive measures, such as arranging meetings with a healthcare provider. Of these six studies, four found statistically significant differences in the video-arm group compared to the control (verbal-only) group. Yet, the remaining two studies found no statistically significant difference in the two groups. Using adapted questionnaires, 28 studies looked at two types of knowledge - subjective and objective. The most common questionnaire used was the Knowledge, Attitudinal and Experiential Survey on Advance Directives (KAESAD), a 30- item true-false questionnaire developed to assess knowledge among 
Running Head: A VIDEO DECISION AID TO INFLUENCE ADVANCE CARE PLANNING professionals. The ACP Nurse Inventory and the Health Care Proxy Role and Responsibilities was also used. Subjective knowledge was described as "feeling of knowing". Objective knowledge was determined by the actual content and organization of knowledge that is held in memory and measured by objective tests of the person's extent of knowledge in a specific subject. Subjective knowledge was assessed by asking participants to give open-ended definitions of ACP and AD. Fifteen studies assessed patients' objective knowledge of the ACP process and knowledge regarding state laws for ACP. Another fifteen studies noted factors associated with the level of knowledge, including socio-demographics characteristics as age, religion, ethnicity, education, and work experience. The authors found that overall, higher ACP knowledge was related to the level of education and work experience. A strength of this study was the review of international studies from Brazil and Portugal. Most of the studies were conducted in the US, where the knowledge of the PSDA may have influenced the increase in the number of Americans completing ADs in the last decade. There were limitations noted in this study. Few studies were found to meet inclusion criteria, which the authors concluded could be the result of the lack of ACP conceptual clarity. Most studies reviewed only one to two aspects of $\mathrm{ACP}$, finding that consistency in understanding of the topic did not exist. In addition, the concept of ACP was "poorly described" in several studies, limiting an accurate evaluation of the actual knowledge that individuals have of ACP. Another limitation of this review is only 15 studies used a structured and valid instrument. Other studies revealed inconsistencies in the instruments used among respondents, which likely negatively influenced an accurate and reliable measurement of knowledge.

Jain et al., (2014) performed a systematic review to evaluate the impact of video decision aid on patient's preferences regarding life-sustaining treatments. The articles for the systematic 
Running Head: A VIDEO DECISION AID TO INFLUENCE ADVANCE CARE PLANNING review were chosen using the Preferred Reporting Items for Systematic Reviews and MetaAnalysis (PRISMA) tool, which outlines standards for conduct and reporting of systematic reviews. The data were assessed for quality of evidence (confidence in effect) using the Grading of Recommendation Assessment, Development and Evaluation (GRADE) framework. The sample included 2,220 patients 18 years of age and older in an inpatient and outpatient setting. A non-video-based discussion was compared to a discussion with the use of a supplementary video decision aid. Results were mixed. Low-quality evidence suggested that patients who use video decision aids were less likely to indicate a preference for cardiopulmonary resuscitation (pooled risk ratio, $0.50(95 \%$ CI $0.27-0.95)$; I2=65\%). However, moderate-quality evidence suggested that video decision aids result in greater ACP knowledge (standardized mean difference, $0.58(95 \%$ CI $0.38-0.77)$; I2=0\%). No study in the review reported on the congruence of EOL treatments with patients' values. No study evaluated the effect of video decision-aids when integrated into clinical care. Strengths of this systematic review include adherence to the PRISMA standards including a thorough literature search and utilizing a systematic approach for categorizing confidence in the effect estimates (GRADE). Limitations noted in this review included that some studies elicited preferences for EOL treatment by limiting EOL choices to two or three options possibly resulting in limited EOL preferencechoice. Included studies also did not report data on ACP-related outcomes, including confidence in decision-making, resource use at EOL, and comparison of EOL care with patient values.

An RCT conducted by El-Jawahri et al., (2016) utilized a video decision aid for 246 patients with advanced heart failure. The intervention participants engaged in verbal discussion regarding EOL goals of care, including life-prolonging care or full interventions, limited intervention care, and comfort care only. The investigators asked participants to view a six- 
Running Head: A VIDEO DECISION AID TO INFLUENCE ADVANCE CARE PLANNING minute video discussing cardiopulmonary resuscitation (CPR), intubation, and ACP checklists. The control participants engaged in only verbal ACP. The study results showed that $22 \%$ of intervention participants chose life prolonging care or full interventions, $25 \%$ chose limited intervention care, $51 \%$ selected comfort care only, and $2 \%$ remained undecided. In addition, $68 \%$ vs $35 \%$ of the intervention group were more likely to decline CPR and intubation and had higher knowledge scores (77\% vs $48 \%$ ) of EOL options. The study outcome determined those who viewed a video were more likely to select comfort care and less likely to choose full interventions. There were several limitations of this study. First, data collectors were not blinded to the randomization, likely lending to bias. However, the authors note that previous randomized studies of ACP have rarely been blinded to alleviate the onus of participants in addressing sensitive topics. Additionally, the nature of such interventions makes blinding challenging. Second, the generalizability of the study was limited due to the sample population being predominantly Caucasian. Third, the video-assisted intervention led to more dialogue between providers and patients discussing goals of care. However, there was lack of information documenting ACP counseling or completion of AD, DNR orders, or hospice use. Lastly, video media content could be manipulative to some viewers resulting in potentially swayed outcomes.

Nurse Practitioner's Role in the ACP Process. Six quantitative studies (Constantine et al., 2018; Dube et al., 2015; Rietze et al., 2016; Rao et al., 2014; Schlegal \& Shannon, 2000; Splendore \& Grant, 2017) evaluated the APRNs role in the ACP process. After recent passing of WV legislation in June 2016 allowing for the signatory provision, performing, and billing by APRNs for ACP counseling, Constantine et al., (2018) performed a retrospective, observational study looking at the impact on POLST form completion in WV. The results revealed APRNs completed $14 \%$ of the 2,992 Physician Orders for Scope of Treatment (POSTS) in WV with 430 
Running Head: A VIDEO DECISION AID TO INFLUENCE ADVANCE CARE PLANNING POST completed in the first year of signatory authority. A majority of completed POST forms (70\%) in WV were done by only 10 APRNs who specialized in community and in-patient palliative care. This finding is congruent with other study results showing that APRNs caring for the sickest patients are more likely to engage in conversation denoting EOL goals of care. Overall, only $2 \%$ of WV's licensed APRNs completed POST forms. However, APRNs were found to more often complete POST forms with DNR orders than MDs or DOs (90\% vs. 77.1\% vs $77.2 \%$ ) including forms with comfort care measures (45.1\% vs. $34.9 \%$ vs $31.2 \%)$. In addition, APRNs completed more "registry ready" forms compared to MDs and DOs $(89.8 \%$ vs. $77.6 \%$ vs 78.9\%). Furthermore, APRNs, compared to DOs, submitted more POST forms for urban dwelling individuals. Since passing of this new legislation, more educational offerings on ACP counseling have been provided to WV APRNs. Limitations of this study included the relatively small numbers of WV residents who submitted the POST forms to the WV e-Directive Registry. Although almost 3,000 POSTs were submitted in the study period, the authors believe a substantial amount of POSTs were endorsed by providers with knowledge in EOL care yet were not uploaded to the Registry. Additionally, the study was conducted in WV, a mostly rural state with the fourth highest median age in the country and historically second highest percentage of adults reporting fair to poor health status of the US, confounding nationwide generalizability, but supporting generalizability to the older and sicker adult population.

Splendore \& Grant (2017) performed a pre-post study design evaluating and measuring factors of understanding, completion, discussion, and dissemination of ADs to a sample of 40 community dwelling participants. This study was undertaken to investigate how interactive community-based multimodal interventions provide opportunities for individuals to engage in the ACP processes. A second aim was to discuss ACP with family members and primary care 
Running Head: A VIDEO DECISION AID TO INFLUENCE ADVANCE CARE PLANNING providers (PCPs) to achieve completion of ADs. An APRN-led workshop featuring the Five Wishes ${ }^{\circledR}$, a legal, valid AD document written for the lay person, was the intervention used in this study. ACP information was presented by verbal, visual, and written modes of communication. The post-workshop survey results showed there was an increase in participant's understanding of LWs and MPOAs. In addition, participants had a greater awareness of the importance in having ACP discussions. One month following the workshop, 38 participants were contacted by telephone. Twenty-two of those contacted reported having completed their ADs. Thirteen utilized the Five Wishes ${ }^{\circledR}$ booklet to complete ADs. Ninety-three percent had discussions with family but only two (13\%) disseminated their AD forms to anyone. This study concluded that when ADs and ACP is presented using a multimodal approach by a trained APRN facilitator, the individual more likely felt the environment was "non-threatening," which led to further ACP discussion between patients and families. The workshop approach enabled participant autonomy and proactiveness in the completion, discussion, and dissemination of their ADs. The Five Wishes® documents were proven to be feasible, acceptable, and effective modes of educating EOL care options to rural-dwelling community adults. A strength noted in the study was the use of the established Five Wishes ${ }^{\circledR}$ program. The authors believed that the familiarity and validity of this program positively impacted the completion of AD. There were several limitations noted in the study. A convenience sample was used which may have affected generalizability of the results. The instruments used were not confirmed valid as they were created based on the principle investigators interest of measure. Most of the participants did not disseminate their information. The authors attributed this to participant bias as the sample population altered behaviors upon realizing they were being analyzed throughout the study. 
Running Head: A VIDEO DECISION AID TO INFLUENCE ADVANCE CARE PLANNING

Rietze et al., (2016) performed a cross-sectional descriptive study in multiple healthcare settings in Ontario, Canada that used a valid and reliable online survey measuring APRN's beliefs, attitude, and implementation of ACP. The results showed that ACP implemented by APRNs were significantly higher in acute care settings than in PCMH settings. Acute care practice settings were more likely to have a policy for ACP in comparison with PCMH practice settings. APRNs were more likely to engage in conversations when their workplace had a policy supporting ACP. More hospital based APRNs perceived that colleagues expected them to engage in ACP with patients, when compared to APRNs in PCMH settings. Hospital-based APRNs were more confident in ACP than APRNs working in outpatient settings. The study concluded that it is essential to acknowledge that organizational culture and support can have an important impact on practice of healthcare providers particularly in outpatient settings. Policies and procedures are needed to apply a standard approach that guides ACP counseling. There should also be a common knowledge among mutual healthcare professionals of where to document AD to maximize information sharing. One strength of this study was a similarity in the target population to previous studies. A limitation of this study was the low response rate by APRNs. An additional limitation was that the study did not investigate the APRN's competency or role for ACP in various practice settings. However, the findings of this study align with previous research results regarding APRN's knowledge, attitudes, beliefs, and prevalence of ACP counseling.

Dube et al., (2015) performed a quantitative, non-experimental, descriptive study surveying selected APRNs from a statewide database. The purpose of the survey was to investigate provider beliefs and perceptions of ACP counseling, demographics, and profession specialty. The study found that most of the APRNs surveyed held master's degrees with 
Running Head: A VIDEO DECISION AID TO INFLUENCE ADVANCE CARE PLANNING specialty certification for adult gerontology and those working in long-term care, inpatient, and community settings were associated with increased ACP counseling. APRNs (79\%) felt additional training would augment their ACP knowledge and continuing education was an influential factor in the likelihood that the APRN would engage in ACP. Additionally, most APRNs were aware of the PSDA. The APRNs who were aware of the federal mandate engaged in ACP discussions more frequently with their patients. Time constraints were found to impact frequency of ACP counseling where a single or urgent care visit is not amenable to the sensitive approach needed to assess the patient's spiritual values and appropriately inform them of EOL treatment options. Limitations of this study included low response to surveys, use of a convenience sample, and little information collected regarding practice specialty and setting. Because the study was conducted near academic medical centers with knowledgeable medical experts, the survey results could have been influenced. The instrument used was the EOLCDQ II scale, which is 15 years old and may not reflect current healthcare decision-making. In addition, APRNs care delivery and patient education have also significantly evolved in the past decades, possibly impacting participant responses to the 15- year-old assessment tool. Lastly, respondents did not differentiate between ACP and ADs, allowing for skewed survey responses.

Rao et al., (2014) investigated factors that influence completion of ADs among US consumers. Survey data from 7,946 respondents measured demographic and socio-economic variables, presence of chronic conditions, regular healthcare visits, and self-reported EOL concerns. Data show $26.3 \%$ had ADs. Lack of awareness was the most frequently reported reason for not having completed ADs. Over two-thirds of respondents less than 54 years of age did not have completed ADs ( $\mathrm{p}<0.001)$. Increased age, higher education, chronic disease, regular healthcare visits, and higher income were factors associated with a greater completion rate of 
Running Head: A VIDEO DECISION AID TO INFLUENCE ADVANCE CARE PLANNING

ADs. Individuals without EOL concerns less likely had completed ADs. The results also uncovered disparities of race and education in the incidence of AD completion, highlighting the need for more education on the necessity in ACP in clinical practice. A strength of the study was its large sample size. However, this study also had several limitations. Participants consenting to complete the mail panel survey were community dwelling, which may have represented selection bias. Because the survey provided self-reported information on respondents' attitudes and behaviors, information was lacking about the number or nature of chronic health conditions or whether respondents had any type of AD (LW or MPOA) already completed. Finally, the authors also note that the survey items included structured responses, which may have influenced participant's answers and overall study results.

In a descriptive, correlational study performed by Schlegal \& Shannon (2000), survey data were obtained from a convenient sample of adult, geriatric, family, and woman's health APRNs in Washington to determine their knowledge of legal guidelines for EOL planning, knowledge regarding the clinical application of ACP, and APRN confidence in counseling patients on these issues. Results showed that $80 \%$ of the APRNs knew that patients preferred their healthcare provider to initiate ACP counseling. The APRNs (61\%) identified ACP as an important aspect of their practice; yet only $39 \%$ routinely conducted such conversations. The authors concluded that APRNs in primary care were ill-prepared to offer adequate and effective ACP to their patients. Interestingly, $85 \%$ of APRNs believed many patients' deaths were prolonged unnecessarily. Twenty-six percent reported that even with a valid AD, they did not withdraw nutrition or hydration at the EOL, for fear of facing criminal charges. Most APRNs $(92 \%)$ indicated ACP education should be a mandatory component in their graduate training. Common reasons that APRNs initiated ACP counseling regularly, included having a greater 
Running Head: A VIDEO DECISION AID TO INFLUENCE ADVANCE CARE PLANNING knowledge of legal guidelines, stronger confidence in their ACP knowledge, higher levels of comfort in counseling patients, and caring for more patients over the age 65 . This study was one of the first to examine APRNs knowledge of legal guidelines and issues pertaining to EOL decision-making. Limitations of the study were the complexity of the knowledge test, which created a challenge for accuracy of results as the test may not have been specific to the participant's regulatory environment. In addition, issues regarding legal relevance are involved, making test items challenging to write. Another limitation is that $25 \%$ of the respondents had misguided legal concerns because they feared legal and criminal repercussion for withdrawing or withholding treatment for terminally ill patients. Lastly, the age of the study is determined to be a limitation. Despite that, findings of this study correlate with more recent studies regarding APRNs perspective of ACP and was the first to look at this issue.

ACP Impact on Outcomes. Only one study of the 11 included in this review examined the impact of ACP planning on patient outcomes (Weathers et al.,2016). The authors of this study conducted a systematic review of RCTs examining the impact of ACP on quality of care and symptom management outcomes in adults greater than 65 years of age across all healthcare settings. In this systematic review, nine studies, totaling 3,646 participants were analyzed using the Oxford Quality Scale, a five-point scoring system to measure the quality and validity of RCTs. ACP information was conveyed using verbal, visual, and written communication discussing EOL preferences and instructions on completing ADs. The aim was to improve selection of proxy for EOL, rather than educating on EOL treatment options. The primary focus was to address ACP outcomes for patient and families. Five of the nine studies determined that variation of methods of ACP increased the likelihood of establishing a healthcare proxy and the completion of ADs. The remaining four studies reported increased patient knowledge of life- 
Running Head: A VIDEO DECISION AID TO INFLUENCE ADVANCE CARE PLANNING sustaining treatment options, congruency in patient wishes with EOL care, reduction in hospital admission from long-term care facilities; and an overall decrease in health resource utilization. This systematic review concluded that ACP communication has great benefit for patients and healthcare staff, however there were limited RCTs evaluating ACP intervention in older adults across multiple healthcare setting. Limitations noted included the use of the Oxford Quality Scale where a score of three or more was considered free of bias. Because the Oxford Quality Scale is more appropriate for scoring drug intervention rather than appraisal of complex health service interventions, so only three studies scored a three or more. In addition, there were no consistencies in the ACP delivery method used within the studies. Just under half of ACP interactions were directed by trained healthcare professionals. Another limitation identified is that only three databases were searched and only studies in English language were included, potentially omitting other important research.

Expert Opinion. Kates (2017) wrote an exploratory article, based on expert opinion that provided APRNs with legislative updates and current resources intended to improve ACP conversations with patients and families. Kates noted that historically, ACP has been coined as a "legal transactional approach" which has evolved into a "communications approach," to help translate patient's goals into ACP documents and portable medical orders. Kates further notes that the IOM reports that the mainstream population is unable to express EOL preferences and that greater than $25 \%$ of all adults have given no consideration to their EOL wishes. Because of these facts, the IOM calls for more open ACP communication between providers and patient to occur earlier in life and before life-limited illness occurs. Kates also highlights the changes made by the Center for Medicare and Medicaid Services (CMS) that took effect January 2016 for the provision of payment for Medicare Physician Fee Schedule, part B and the Hospital Outpatient 
Running Head: A VIDEO DECISION AID TO INFLUENCE ADVANCE CARE PLANNING

Prospective Payment System for voluntary ACP by providers (physicians, APRNs, and physician assistants) in the context of illness or at an annual wellness visit. Kates reviews the CMS delineation of Current Procedural Technology (CPT) codes and guidelines that structure ACP interactions. There are no restrictions or limitations on the number of uses of CPT codes for individual patients. Kates asserted that patient's "not feeling sick enough" and preferring to focus on staying alive was a common reason to defer ACP dialogue. Hence, Kates reviews the resources that have been developed for patients and families to better understand the ACP process, including the Conversation Project and Vital Talk.

\section{Synthesis}

Video decision aids supplement ACP counseling and educate the patients and families on EOL treatment options. However, the incidence and prevalence of their use is still low in all clinical practice settings. Healthcare provider's lack of education and awareness of ACP seems to negatively impact ACP conducted in outpatient settings. Patients who participate in video intervention concurrent with verbal narratives are more likely to have a higher mean of knowledge and productive ACP conversations with providers and families, compared to those receiving verbal interventions alone. APRNs in all clinical settings can play an influential role in ACP, most notably those APRNs who work in specialty palliative care. Organizational culture as well as healthcare regulation also influences ACP initiated by APRNs. Recently, laws and reimbursement have incentivized the provision of ACP.

\section{Evidence-Based Best Practice to Address the Problem}

Evidence-based practice integrates research findings with clinical judgment and offers guidance and recommendations for medical and nursing practice that improves quality of care and optimal patient outcomes (Larrabee, 2009). There are various programs that have established 
Running Head: A VIDEO DECISION AID TO INFLUENCE ADVANCE CARE PLANNING evidence-based guidelines to shape a multimodal approach to ACP. The Center for Disease Control (CDC) through their Healthy Aging campaign offers several online evidence-based resources for clinician and patient education which facilitate successful aging and discussion of EOL goals. The Dartmouth Atlas Project's, End of Life Care session is a research project that used Medicare data to provide information and analysis about national, regional, and local healthcare markets. These research efforts have informed the CDC guidance on EOL care issues and helped key stakeholders improve their understanding of the health care system to form a foundation for the ongoing efforts to improve health (CDC, n.d.).

The West Virginia Center for EOL Care (WVCEOLC) (2019) is a funded initiative that provides education for residents of $\mathrm{WV}$ and providers on ACP, ADs, and state and national laws around EOL. The WV e-Directive Registry, stores outputs of ACP including ADs and medical orders such as POSTs and DNR cards. In collaboration with the WV Network of Ethics Committee (WVNEC), WVCEOLC offers evidence-based training manuals and continuing education to clinicians. Recently, the WVCEOLC was recognized by the US Government's Accountability Office as a national leader in ACP with the development of the Registry. WVCEOLC has also been recognized by The New York Times, American Association of Retired Persons (AARP), the National Quality Forum (NQF), and the IOM for championing an innovative system that allows clinicians to have easy access to patients' ADs through the eDirective Registry (WVCEOLC, 2019).

Respecting Choices® (2017), developed with support from the Gunderson Health Care System is one of the leading educational opportunities for providers for learning ACP skills. Their program is used to educate clinicians on the steps of the ACP process and how to engage patients throughout the process. Their conversation and interview strategies have been supported 
Running Head: A VIDEO DECISION AID TO INFLUENCE ADVANCE CARE PLANNING through multiple studies which have been published as white papers and in peer-reviewed journals (Respecting Choices $\left.{ }^{\circledR}, 2017\right)$. A three-step systems approach which offers a conversation and interview template tool is recommended (See Appendix A) using guidelines from the Agency for Healthcare Research and Quality (AHRQ). The First Steps® phase offers recommendations on conversations between practitioners and healthy adults facilitating forward thinking by those who have not considered EOL treatment provisions. The Next Steps® phase helps individuals with advanced illness to identify goals of care in the event of disease complications that could potentially lead to poor outcomes. Finally, Last Steps® offers guidance to clinicians caring for patients whom the "surprise question" is considered for completion of the POST form and medical orders. The surprise question is a simple test to identify patients at high risk of death in the coming year and is asked by the provider to oneself to determine if the patient is likely to die in the next 12 months. If the provider would not be surprised if the patient died in the coming 12 months, then ACP and possible POST completion is strongly recommended. The "surprise question" has been adopted into hospice and palliative care program frameworks. (White, Kupeli, Vickerstaff, \& Stone, 2017).

ACPdecisions.org is a web-based, non-profit physician-led organization that provides evidence-based educational resources for clinicians and patients via video decision aid tools. These videos have undergone rigorous review by medical experts and researchers (Advance Care Planning Decisions, n.d.). The site provides various videos focusing on EOL and ACP that are available in 20 different languages. Five videos are narrated in lay terms and available free for patients and clinicians. The videos are, "The Conversation", "What is Palliative Care", "Talking to Your Doctor", "POLST", and "Patient Checklist". ACPdecisions.org asserts that people retain $95 \%$ of information when watched in a video compared to only $10 \%$ retained when reading in 
Running Head: A VIDEO DECISION AID TO INFLUENCE ADVANCE CARE PLANNING text (Advance Care Planning Decisions, n.d.). Through the evidenced-based tools offered on the site, healthcare organizations can easily implement a strategy that encourages shared decisionmaking and augments ACP in various clinical settings.

Another evidence-based resource that guides clinicians in ACP is VitalTalk.org. VitalTalk disseminates ACP research and offers evidence-based, innovative, and interactive skills-development courses to improve clinician-patient communication. VitalTalk contends that discussing end of life goals is a pivotal communication in the care of seriously ill patients. The website offers REMAP as a framework for these conversations. REMAP provides guidance on how to emphasize dialogue depending on the patient's health status. The important conversation concepts focused in the framework include Reframe, Expect emotion, Map out goals of care, and Propose a plan (VitalTalk.org, n.d.). VitalTalk is readily accessible to clinicians and patients and offers a sound scientific evidence supporting ACP across settings.

\section{Theoretical Framework}

The theoretical framework being used to structure this project is Kurt Lewin's Change Management Theory. This theoretical framework refers to a “Three Stage Model”. The model encompasses three distinct phases known as unfreezing, change, and refreezing (See Figure 1). The "Force Field Analysis" is a framework within the model that explains the driving and resisting forces that affect change. The theory can be used to understand change as it impacts people, groups, or organizational processes. Many health care organizations have used Kurt Lewin's theory to understand human behavior as it relates to change and patterns of resistance to change. This particular quality improvement project focuses on an organizational practice change that may be impacted by driving and resisting forces and will use Lewin's theory throughout its implementation. 
Running Head: A VIDEO DECISION AID TO INFLUENCE ADVANCE CARE PLANNING Key Elements

Lewin argued that successful businesses tend to be constantly adapting to their environment and changing. (Kaminski, 2011). Lewin proposed three essential phases to the change model framework- unfreezing, change, and refreezing.

The first stage in the model is "unfreezing". In this stage the change agent seeks to find a way to facilitate the acceptance of changing the "old ways" or acknowledgement that change is needed, essentially "unfreezing" the forces that sustain the current activities. Identification and implication for change is conveyed through open dialogue and educational activities that cultivate team building as well as personal and professional development. If the need for change is clear and evident, buy in will be easier to obtain.

The second phase in the model is the actual "change" phase. This includes a change in behaviors, thoughts, and mindsets that lend to acquiescence of the "new way". In this stage, the participant of change will acknowledge that the change is more beneficial than past practices. This phase also entails the restructuring and implementation of the change so that sustainability is attained. Instituting sustainable practice mechanisms assures the successful completion of this stage.

The third and final phase of this model is the concept of "refreezing". In this stage there is establishment of the new process which is recognized as a standard in care or operating procedure. Esteemed leadership, merit rewards, and implementation of policy is crucial in this stage to prevent regression of the new change to previous practices.

Lewin also describes a Force Field Analysis model (See Figure 2) that depicts the positive and negative forces that influence change, also known as the driving forces and resisting forces. Positive forces propel behaviors that benefit change. Negative forces impede the actions 
Running Head: A VIDEO DECISION AID TO INFLUENCE ADVANCE CARE PLANNING necessary to implement and sustain change. Driving forces include internal and external forces that support change. Driving forces positively influence and sustain change that increases productivity, improves patient outcomes, and reduces health care costs. Resisting forces impede change. The driving forces must exceed the restraining forces for successful change to occur (Kaminski, 2011). Internal driving forces may include culture, leadership, practice standards and organizational policy. External driving forces may include customer need, technological demands, and health care regulations. Resistance to change is normal but it leads to disruption in the familiar workflow or environment and causes stress among those who will be impacted by the change. This resistance can be a barrier in the achievement of the goal. A common reason for this resistance is the individual's concern that the proposed change may bring misunderstanding or uncertainty. Poor practice habits, health care costs, ineffective workflows, and technology illiteracy are examples of restraining forces. Successful change occurs when the driving forces are supported, and the resisting forces are debilitated. Once that process is complete, refreezing of the system change can occur and the change process is successful.

\section{Project}

\section{Institutional Review Board}

This project was reviewed and approved as an expedited study by the West Virginia University (WVU) Institutional Review Board (IRB) on November 1, 2018. There was limited risk to the participants. Informed consent was obtained from those who agreed to participate in the intervention phase of the project. There was no deception used as part of the project implementation.

\section{Description}


Running Head: A VIDEO DECISION AID TO INFLUENCE ADVANCE CARE PLANNING

This was a performance improvement project aimed at improving completion rates of ADs and medical orders after ACP by an APRN. The APRN used a video decision aid tool in ACP interactions in addition to verbal description counseling. The project investigated the impact of adding a video decision aid to the standard of care (SOC) ACP conversation only. AD and medical order completion rates were measured for 42 elderly residents of WV during their Medicare Wellness Visits (MWV) to determine the effect of the video decision aid on the AD and medical order (POST) completion rate.

The Video Decision Aid. The video titled, “The Conversation”, obtained from the ACPdecisions.org website was used for this project intervention. The content of the video outlined three important steps the patient should consider when initiating EOL conversations: (a) Reflect on wishes, values, cultural and spiritual beliefs that may influence EOL care while considering the type of medical treatment desired; (b) Talk to loved ones about these issues and review AD documents (MPOA, LW \& POST) and; (c) Talk with the healthcare provider regarding the three levels of medical treatment which includes life-prolonging care, limited medical care, and comfort care. This video is applicable to various clinical settings and available in 20 different languages. ACPdecisions.org has established that their videos have clinical significance as evidenced by 20 RCTs, involving over 5000 subjects performed in various clinical settings. These RCTs are available for review and are US published on the ACPdecisions.org website (Volandes et al., 2016). According to this supporting evidence, there was a higher incidence of AD completion among participants in both the ambulatory and acute care setting for those who viewed one of the videos. Additionally, the videos have a positive impact on participant's increased level of knowledge of ACP and preference to forego aggressive 
Running Head: A VIDEO DECISION AID TO INFLUENCE ADVANCE CARE PLANNING

EOL care, resulting in fewer number of deaths in the hospitals, increased hospice utilization, and decreased health care costs.

Setting. This performance improvement project was performed in an outpatient primary care clinic in a rural county in the Eastern Panhandle of West Virginia.

Inclusion Criteria. Inclusion criteria consisted of adults aged 55 and older who were (a) WV residents, (b) Medicare beneficiaries, (c) an established patient of the clinical site where the performance improvement project was implemented and (d) did not currently have an AD or associated medical orders. Initially the targeted age for inclusion was 65 years and older. However, it was noted during the early phase of the study that the clinic's Medicare beneficiary population was age 55 and older, thus the inclusion age was changed to 55 years. The IRB protocol was amended and approved on March 7, 2019 for this change. Patients who spoke other languages were also included as the video support tool was available in multiple languages. Exclusion criteria included: (a) patients less than age 55, (b) patients who already had existing AD on file, and (c) patients who had additional insurance other than Medicare.

Sampling Plan. The Joint Commission's sampling guidelines were used to determine adequate sample size needed for this quality improvement project. There were 234 patients who attended their scheduled MWV in the project site for the year prior to implementation of the study. It was deduced that the number for the current year would be similar. In a population of 101 to 500 targeted cases, 50 cases would be an adequate sample size (Larrabee, 2009). Therefore, 50 cases were determined as an adequate sample size for our expected patient population of 234 patients.

Recruitment and Enrollment. A standard letter was sent by the office staff to schedule the annual MWV, as done in usual care. Once the appointment was scheduled, a consent letter 
Running Head: A VIDEO DECISION AID TO INFLUENCE ADVANCE CARE PLANNING

and a study explanation letter following IRB guidelines was mailed to prospective participants.

The patients were asked to bring a copy of the consent to their appointment. A notation was

made on the schedule to indicate that this patient has been identified as a prospective participant.

If the patient forgot to bring the informed consent, the APRN provided a second copy of the

consent if the patient wished to participate. It was requested in the letter that patients begin

considering a MPOA and have that individual in attendance at the visit to participate in the ACP interactions.

Sample. There was a total of 70 study consents mailed to potential participants who met inclusion criteria. Of those who were scheduled a MWV with the APRN, eight did not attend nor cancel, six cancelled, and two rescheduled their MWV appointments outside of the project implementation time frame. In total, 54 patients attended their scheduled MWV appointment. Of the 54 patients, 42 consented to the study. The average age of the sample population was 72.4 years with an age range of 55 to 96 . Eighteen males and 24 females participated in this performance improvement project. Although not significant, the willingness to complete AD was influenced by the participant's gender. More females than males completed AD (54.5\% vs 45.5\%). National statistics also show women more often than men take actional, proactive steps in healthcare decision-making, despite men with a higher incidence to develop serious illness (Lounsbury, 2019). The education level of each participant was noted. Studies show that the level of education can influence ACP knowledge (El-Jawari et al., 2016). In this case, level of education was not measured to indicate intellect or ACP understanding, rather noted to demonstrate diversity among this patient population. Of the 42 participants, $15.4 \%$ had less than a high school education, 50\% were at least educated at the high school level, $15.4 \%$ received 
Running Head: A VIDEO DECISION AID TO INFLUENCE ADVANCE CARE PLANNING some college, $11.5 \%$ held a college degree and $7.7 \%$ of participants held a graduate level education.

Acceptance of Participation. Of the 29 participants randomized to the intervention group, 18 agreed to participate. Twenty-five participants were assigned to the control group, 24 agreed to participate. One patient meeting criterion for the "surprise question" completed a POST with preference for DNR with comfort measures. Interestingly, there were a variety of reasons for participation refusal: (See Table 1).

1) Nine (16.7\%) patients attended the scheduled visit without a family member/spouse, therefor did not want to participate in the video viewing or ACP counseling until the opportunity arises for the designated family member to be present. However, the patient did agree to take home a packet of blank AD documents and allowed the APRN investigator to briefly review the content. 2) One (1.9\%) patient was "not ready to think about EOL" despite being afflicted with multiple chronic medical disease and high likelihood of poor health outcomes. In this instance, future opportunities for ACP discussion were offered with the APRN outside of the time frame for this study.

3) Five (9.3\%) participants had a strong belief that the family will "take care of everything" if unable to make EOL decisions. They were steadfast in this decision even after an overview of the likely burden placed on family members when in the position to make difficult EOL treatment choices.

4) Interestingly, two (3.7\%) patients noted they did not "want to give WVU any information" however, they did not offer further explanation for this reason. The APRN clearly and concisely explained the purpose of the research study and the potential benefits participation may bring to the patient and family. 
Running Head: A VIDEO DECISION AID TO INFLUENCE ADVANCE CARE PLANNING

5) Three $(5.6 \%)$ patients of advanced age $(M=85)$ had sensory deficits, which impeded their ability to observe or hear the video content, therefore refusing to participate. These patients agreed to engage in the verbal counseling.

6) Three (5.6\%) patients who received study consents already had completed AD at home, not yet provided to the medical office. Also, one (1.9\%) patient brought with him recently completed $A D$ done in response to receiving the study consent, therefor did not feel compelled to participate.

APRN Preparation. In preparation to engage patients and families in ACP, the APRN participated in an eight-hour ACP facilitator certification course offered by the Respecting Choices ${ }^{\circledR}$ Program at a regional Medical Center. This training was completed to increase the professional competence and confidence in providing skilled ACP facilitation and delivering care that is consistent with an individual's goal, values, and beliefs (Respecting Choices ${ }^{\circledR}$, 2017). Additionally, a one-hour webinar course produced by the WVCEOLC was viewed for guidance on ACP, AD and medical order completion, and billing related to ACP. (WVNEC, n.d). Additionally, a thorough review of the legal and ethical parameters by the CDC, CMS, WV Health Ethics and Law, National Hospice and Palliative Care Organization, and Stanford Law Review publications was performed to integrate a breadth and depth of regulatory information when educating patients, families, and other clinicians. Lastly, the APRN received commission as a Notary Public in WV on June 26, 2018 for the benefit of providing notary services for the patient at the time of AD completion, as required by WV law.

Staff Education and Communication. Education regarding the quality improvement project for the office staff and other key players was provided by the APRN investigator. An informative 10-minute session during a scheduled staff meeting with follow up throughout the 
Running Head: A VIDEO DECISION AID TO INFLUENCE ADVANCE CARE PLANNING

duration of the study was provided to address concerns or constraints and realign interventions with project goals and objectives. Dissemination of project information was done via organization email, staff meetings, and face to face conversation during the study to inform other clinicians of the proposed project. Future dissemination to a wider audience will be sought by submitting abstracts and manuscripts to peer-reviewed nursing journals and palliative care conferences.

Intervention. After informed consent was received, the participants were randomized to their respective intervention or control group by means of a coin toss. If the coin landed on "heads" the participant was assigned to the intervention group and if the coin landed on "tails" the participant was assigned to the control group. The intervention group viewed the five-minute video, "The Conversation" and received verbal discussion of ACP. The verbal discussion of ACP or standard ACP counseling was founded on the evidence-based conversation principles developed by the Respecting Choices ${ }^{\circledR}$ program. The control group received only verbal discussion of ACP. All patients and family members were given adequate opportunities to have questions and concerns addressed by the APRN regardless of their group.

Data collection. Information was collected using a tool ( See Appendix B) developed to note demographics (age, ethnicity, education level), type of intervention (video plus verbal description or verbal discussion only), code status, and whether or not an AD or medical order was completed (MPOA, LW or POST). As part of usual care during the annual MWV, the APRN documented the face to face ACP interactions using the standard template and time-based billing CPT codes established by CMS.

Office staff consisting of medical assistants (MA) and license practical nurses (LPN) were asked to upload the forms into the patient's electronic medical record (EMR) and the WV 
Running Head: A VIDEO DECISION AID TO INFLUENCE ADVANCE CARE PLANNING

e-Directive Registry website, per patient opt-in. No additional skills were needed by the staff as their role in the project was minimal. There were no extraordinary confidentiality, privacy, or security issues determined nor any technical constraints identified.

Follow Up Plan. For the patients who chose not to complete AD or medical orders a notation was made in the MWV documentation note that ACP documents were not completed. This should prompt other providers that ongoing ACP discussion should occur at subsequent clinic visits. Additionally, the patients were offered a future appointment with the APRN that would follow a same day appointment with the primary care provider for the purpose of continuing ACP conversations.

\section{Application of Theoretical Framework}

Lewin's Change Management Theory framework provided guidance in managing organizational and behavioral factors that influence a practice change. The three- step model offered a simple and practical approach to understanding a change process. The three-step approach entails the concepts of "unfreezing", "change", and "refreezing". In the "unfreezing" phase the change agent seeks to facilitate a change in the "old ways" through dialogue and education of the key players (Kaminski, 2011). The APRN investigator identified the need to transform ACP from the standard approach and set standards for engaging in successful EOL conversations that are embedded throughout the disease spectrum. Also, a vital step in this phase was the APRN working to educate the office staff and other practitioners on the ineffective nature of the current practice paradigms. The APRN investigator highlighted the importance of a sustained quality practice change accomplished through the integration of a multimodal approach to ACP. 
Running Head: A VIDEO DECISION AID TO INFLUENCE ADVANCE CARE PLANNING

The "change" phase of the project was successful. In this phase there is a change in the behaviors, thoughts, and mindsets that lend to the acceptance of the "new way" (Kaminski, 2011). There was a vested interest by other clinicians in the clinic to adopt alternative multifaceted methods that explicate ACP education. It was the consensus of the key stakeholders that providing tools, like videos, simplifies the ACP process and enriches patients' and families' forward thinking of EOL goals of care. Consequently, patients and their families were able to distinguish treatment preferences and lessen their emotional burden when doing so.

The "refreezing" phase of the Change Management model entails restructuring and implementation of the change (Kaminski, 2011). The APRN investigator's leadership in advocacy for an updated policy was essential to substantiate a practice change that aligned performance improvement with the organization's mission. This policy should make provisions for ACP conversations routinely being addressed at every MWV as methodically as other preventive services. Also essential in this phase was the incorporation of an evidence-based framework for conversation templates that propose valuable EOL dialogue. These conversation strategies were formulated through agencies that work to develop and support such frameworks, such as the Respecting Choices ${ }^{\circledR}, \mathrm{CDC}, \mathrm{WVEOLN}$, and Hospice and Palliative Care Organization. The providers in the clinic were educated on the availability and significance of these guidelines in providing scientifically sound ACP counseling.

The Force Field Analysis model provided direction in the assessment of situations that impacted the project. Internal and external driving and resisting forces that influence the personal and organizational behaviors were identified. The driving and resisting forces directly influence the practice change process within a larger system. Internal driving forces are identified as culture, leadership or practice standards (Kaminski, 2011). Identification of the need for change 
Running Head: A VIDEO DECISION AID TO INFLUENCE ADVANCE CARE PLANNING

regarding the clinic's current practice standards in ACP was the primary driving force for this pilot project. During the implementation phase of the study, a second driving force was recognized as a potential shift in the organization's perceived value toward ACP. The clinician's demonstrated interest and motivation in improving the ACP process that encourages patient and family involvement in shared decision-making and increasing number of AD that are completed. An external driving force proved to be the APRN student's breadth and depth of knowledge of the regulation, ethics, and evidence-based guidelines surrounding the ACP process, which richly augmented the cursory verbal discussion that has been traditionally viewed as the standard of care.

Lewin hypothesizes that a successful change occurs only when current behavior is replaced by desired behavior but resisting forces exist that potentially obstruct successful transition of desired behaviors (Kaminski, 2011). Although the implementation of the study was successful and the results showed positive correlation between the interventions and outcomes, there were resisting forces identified. Only 42 patients consented to participate in the study. A myriad of reasons for refusal of participation were given and these were discussed in the “acceptance of participation" section of this report. The high no-show and cancellation rate of MWV appointments prohibited a larger sample size of participants. Finally, providers did not have adequate time at scheduled MWV to systematically and effectively engage in ACP dialogue with patients and families, which historically has been a common hindrance throughout all clinical practice settings. Most of the MWV appointment time is spent reviewing health maintenance and preventive services essential for a patient's wellness. Although these resisting factors were believed to be encumbered on the study results, the valuable qualitative data gleaned from them can contribute to the design and methodology of future like studies. 
Running Head: A VIDEO DECISION AID TO INFLUENCE ADVANCE CARE PLANNING Feasibility Analysis.

Recognition and support of the motivating factors for establishing a practice change is vital for productivity, sustainability and liberation of performance improvement strategies within an organization. This performance improvement practice change is believed to bring valuable and potentially sustainable resources to the organization that will improve clinician-patient communication, enhance education of providers and integrate best practice standards in EOL care. These outcomes align with the health care organizations' mission and vision. A successful practice change will positively impact the patient by increasing autonomy and decreasing the burden on family to make difficult EOL medical choices. The process change is expected to ultimately expand the number of adult WV residents who complete AD. In addition, there were several benefits to the project that will lead to best practice standards in patient care. These benefits were realized through integrating a growing knowledge within the medical and social communities on empowering patients and families to have shared decision-making in EOL goals of care. The video decision aid is simple and cost effective yet can dynamically change the ACP process. Because the video and other pertinent ACP materials were obtained free of charge, the project was cost effective and easy to implement. Moreover, there is publishing potential of the results as few studies were found that researched the utility of a video on ACP interaction in an outpatient setting. The results of this study have contributed to the opportunity in determining the advantage of such a decision aid in clinical practice.

Consequences of conducting the project in this clinical setting have been considered. First, there was a minimal change in the staff's workflow during the participant's MWV appointment as previously discussed. Secondly, adaptation in technology requirements with adding quality measures to the EMR system was needed. The organization's Epic trainer 
Running Head: A VIDEO DECISION AID TO INFLUENCE ADVANCE CARE PLANNING

educated the APRN investigator on this process. Consequently, results of this project can quantitatively and qualitatively prove the benefit of a practice change in the health care provider's practice if the video decision aid is adopted and implemented.

\section{SWOT Analysis.}

A SWOT analysis was performed for the project to consider the factors that influence successful practice change and stakeholder buy-in. This analysis broadly outlined the internal and external benefit and burden of performing the study. Internal positives are benefits that effect the interventions that occur within the confines of the project. The benefits identified will improve several areas of clinical practice, including patient care, patient-provider communication and the ACP process itself. Also, of benefit will be empowerment of patients to begin considering goals of care at the EOL and involving chosen family members. As there remains a national and state-wide call for the expansion of adults completing $\mathrm{AD}$, a market exists for a video decision aid tool in clinical practice to offer a multimodal approach to ACP counseling.

Internal weaknesses were identified within the scope of the project. Internal weakness are factors that may negatively influence the implementation of the study. Office staff not agreeing to perform the tasks requested was considered an internal weakness. Also, the office staff may incorrectly title the AD documents after uploading in the EMR making it difficult for providers to search and locate them when needed. Moreover, despite the additional education and an open and honest communication approach, the patient and family may have an unwillingness to discuss EOL goals of care. Also, the possibility that some clinicians may view the implementation of a video as a substitute for face-to-face verbal discussion. This is another project weakness. 
Running Head: A VIDEO DECISION AID TO INFLUENCE ADVANCE CARE PLANNING

External opportunities were also identified. External opportunities are domains of the project that directly and positively influence extrinsic factors. The practice change may bring patient satisfaction when EOL care decisions are known to the provider and family. There could also be a cost- effective benefit for the patient and family by preventing unnecessary expense for futile hospitalization and medical intervention at the EOL. The organization may potentially realize a cost benefit. In some cases, patients do not have the financial means to afford expensive EOL care, in which case the organization will absorb the incurred expense. A positive impact is the diversity of the video and its functionality in various clinical settings- outpatient, inpatient, hospice care, long term care, or any setting where ACP discussions occur. Another important benefit of this project is that it will decrease the burden on families and providers to make EOL decisions that may contradict the patient's wishes.

Lastly, external threats had to be considered. External threats are factors that occur outside the boundaries of the project implementation, which could negatively impact the study results. Because the video was obtained free of charge through a web-based organization, there is a possibility it may become unavailable or eventually incur a charge for future downloads and updates. In that case, the organization will have the additional expense.

Impact Analysis. An impact analysis was performed for the proposed project. It was determined that overall there was low impact on the key team members and organization. Training of the team staff members entailed a 10-minute session to overview the project and discuss expected roles. There was no unreasonable impact on the APRN investigator's role in conducting the ACP counseling. Furthermore, the proposed change had minimal impact on the organization's resources and financial contribution as outlined in the budget proposal (See Appendix C). 
Running Head: A VIDEO DECISION AID TO INFLUENCE ADVANCE CARE PLANNING

Sustainability. Needs for feasibility and sustainability of the project included an electronic prompt in the EMR to notify staff when ACP hasn't been completed. The technical feature of adding "Advance Care Planning” to the patients EMR face sheet will prompt key staff to implement the video, if successfully adopted, when ACP counseling is necessitated.

Functional requirements required to carry out this project had minimal demands on team members. The office staff had a minimal change in workflow to upload the AD documents to the EMR and WV e-Directive Registry. This took an average additional five minutes at each study participant's MWV. Uploading the documents into the EMR automatically updated the patient's snapshot face sheet by nature of the EMR program design. ACP discussion, assisting patients with completion of $\mathrm{AD}$, data collection, documentation, and notarizing was done by the APRN investigator. There were no additional demands on the patient and family, only to view the video and voluntarily discuss EOL goals of care.

The provider's buy in and adoption of the intervention tool in the PCMH is crucial to the sustainability of this performance improvement project. Demonstration of how the video support tool aligns patient centered goals and best practice standards of the health care organization should provide incentive for acceptance of a process change. Also, the video decision aid is efficacious and improves patient's knowledge of ACP concepts, therefore provider time during visits can be spent helping patients adapt a plan that focuses on values and wishes for EOL goals of care. Patients and families participating in this study are expected to gain the benefit of an enriched ACP experience though the use of the video. Enlightening on factors of respect for patient's EOL wishes, better quality of life, decreased burden on the family, and expense of life saving healthcare are benefits of this initiative that may encourage patient buy in of participation and sustainability of this project. 
Running Head: A VIDEO DECISION AID TO INFLUENCE ADVANCE CARE PLANNING

Resources. The project has great opportunity to augment the health care system to support patients at the EOL in a variety of ways. The project provides conceptual clarity and demonstrates the importance of ACP before a serious illness or injury occurs. The project also provided networking opportunities with other disciplines and leaders in the healthcare system to develop a consistent knowledge base and practice standards for addressing EOL goals of care. The key stakeholders vital to the project were the organization's administration, office staff, nursing staff, informational technology, project committee, and patients and families.

Project Committee. The project's chair was the primary investigator and the APRN acted as the co-investigator. In addition to the Chair, the committee consisted of a second faculty member and a content expert. The expected roles of the committee included the chair as the point of contact for the development of ideas, expertise recommendations, guidance and critical feedback throughout the development of the project. The Chair also gave approval for submission to the internal review board (IRB). The second faculty member provided guidance and feedback on project development, communicated with the Chair and the APRN, gave critical feedback, provided suggestions, and recommendations. The content expert was the on-site contact for project issues, recommendations, logistics, and provided clinical expertise on the study topic. A formal and informal communication plan with the committee and organization's key players was developed and followed (See Appendix D).

Budget. A budget was developed to outline the estimated expense incurred by this project. The total APRN contribution to the project was $\$ 673.00$. The student paid $\$ 49.00$ to view an informational webinar produced in part by the WVNEC (2019) on best practice for ACP counseling and AD completion. An i-Pad was purchased by the APRN for $\$ 539.00$ as the laptop supplied by the organization's informational technology department created technical issues with 
Running Head: A VIDEO DECISION AID TO INFLUENCE ADVANCE CARE PLANNING

viewing the video. An estimated $\$ 50.00$ was spent on providing lunch to the office staff to discuss the project overview. Project office supplies were estimated at $\$ 35.00$.

The organization's in-kind contribution was an estimated \$282.25. Most of the expense was an approximate accrual from office staff salary generated through work hours to assist with the project. An estimated cost of $\$ 187.50$ for 12.5 work hours was needed for the medical assistant (MA) or licensed practical nurse (LPN) to carry out their roles. The organization provided the various office supplies at the cost of $\$ 94.00$. Basic materials such a paper, pen, printer ink was needed to generate patient letters and documentation. The video aid was a free download from the website, ACPdecisions.org (Advance Care Planning Decisions, n.d). An estimated five videos will be needed to download on an i-Pad or laptop at other affiliated clinical practice settings if this video tool is adopted by the organization. The AD documents were also provided free of charge by the WVNEC. Additional free copies can be downloaded and printed as needed. Additionally, the APRN investigator utilized her own office space in the clinical practice setting where the project occurred. No additional space was needed.

Costs and Benefit. The organization generated revenue as a result of this project as the CMS CPT codes were used to bill for ACP interactions. If the APRN investigator spent less than 30 minutes face to face with the patient or family member, CPT code 99497 was used. CMS reimburses $\$ 86.00$ for physician and $\$ 73.00$ for advance practice providers (APP) for this code. CMS allows billing for a documented additional 30 minutes of face to face interaction using CPT code 99498 and will reimburse $\$ 75.00$ for physician and $\$ 64.00$ for APPs (CMS, 2018). All participants who agreed to either the video intervention and ACP counseling or verbal counseling alone received less than 30 minutes of ACP interaction time totaling $\$ 4050.00$, offsetting organizational expense for this study by a positive revenue of $\$ 3767.75$. Despite only 
Running Head: A VIDEO DECISION AID TO INFLUENCE ADVANCE CARE PLANNING

42 patients agreeing to study participation, a total of 54 patients received some degree of ACP interaction. Appropriate documentation and billing codes were used for all patients who engaged in ACP at the MWV.

\section{Congruence to Organization's Strategic Plan.}

The organization's mission and vision statement structured the goals, aims, and objectives of this project (See Appendix D). The mission of West Virginia University Medicine is "To improve the health status of Eastern Panhandle residents by providing excellence in health and wellness services, expanding access to care, and participating in the education of health care professionals" (WVU Medicine, 2018). This mission supports the project's primary goal of 50 WV residents greater than 55 years old completing appropriate Advance Directives after viewing a five-minute video of Advance Care Planning options at their annual MWV.

The primary goal is structured by three process objectives. The objectives of the project were guided by the organization's visions. The first vision of "a patient centered system of care" is focused by the project objective to increase the number of elderly patients in WV who engage in ACP and complete AD in their PCMH. The second vision, "development of new approaches to improve healthcare, including team-based models of care, expanding WVU clinical and translational research" supports the second project objective- to utilize an evidence-based decision support tool that will sustain practicality and validity and augment clinician's counseling of ACP and EOL issues. The third vison, "a culture of performance and excellence throughout the network" underlines the third project objective of aligning best practice for the WV geriatric population with current practice standards of the health care organization.

Evidence of Key Site Support. 
Running Head: A VIDEO DECISION AID TO INFLUENCE ADVANCE CARE PLANNING

On August 8, 2018, a letter of support (See Figure 3) was obtained from the Dean of West Virginia University Medicine, Eastern Division giving approval to conduct the project at the suggested clinical practice setting. A project summary, proposed budget, and SMART outline was provided and reviewed. The organization's administration, clinical providers and office staff fully supports the conduct and utilization of research that may lead to quality practice change within the clinical settings. Provider and staff participation in research is encouraged within the health care organization. Periodic updates were given to the Dean as well as other clinical providers and key players interested in the outcome of this project.

\section{Project Goal and Objectives}

One program goal and three process objectives were formulated to establish criteria and standards for which to evaluate the outcome of this study. The primary goal was: By the conclusion of this project, $50 \mathrm{WV}$ patients age 55 years or older will complete AD after viewing a five-minute evidence-based video on ACP at their annual MWV in an outpatient clinic. The three process objectives were set to support the primary goal and shape the direction of the interventions required to investigate the influence of the video decision aid in ACP. The project plan was modified throughout implementation to align interventions necessary to meet the objectives. A data collection plan (See Appendix E) was developed that details the expected outcome of each objective.

\section{Process Objectives}

Process Objective 1. At completion of this project, there will be an increase in the number of $\mathrm{AD}$ completed in the PCMH setting where the project was led. 
Running Head: A VIDEO DECISION AID TO INFLUENCE ADVANCE CARE PLANNING

Process Objective 2. At successful completion of the project, a video decision aid will be assimilated into patient-provider ACP interactions to augment EOL care education and promote AD completion. This approach employed Lewin's Three- Step Change Theory model.

Process Objective 3. After the project, the key principles derived from the evidence-based conversation and interview templates will become a standard in ACP conversations. By doing so will align the new process change with best practice standards of the health care organization.

\section{Future Goals}

In addition to the primary goal and objectives, two future goals were identified during the planning phase of this project. Although not components of this study project, these are believed to be vital to promote long-term sustainability of a comprehensive approach to ACP.

Dissemination of this project's findings may bring awareness and educate other clinician's and residents on the importance of forward thinking in EOL planning while shared decision-making and consideration of one's values and wishes can be realized.

Future Goal 1. Within two to three years, $80 \%$ of state-wide practitioners (MD, DO, APRN, PA, SW) will self- educate on health ethics and laws as they pertain to ACP and assimilate those guidelines into organizational policy and EOL counseling as standard practice in the PCMH setting. This outcome can be evaluated through surveying of WV's healthcare providers on their understanding of the clinical and legal structure and its impact on frequency of ACP discussion.

Future Goal 2. Within five to seven years, $75 \%$ of elderly WV residents will complete AD in the PCMH setting. Currently, 50\% of WV residents have completed AD (WV Rural Health Association, 2013). This outcome can be measured through data mining of the WV eDirective Registry database and survey of the state's elderly residents. The interventions in this 
Running Head: A VIDEO DECISION AID TO INFLUENCE ADVANCE CARE PLANNING

pilot study have proven to be effective in enhancing a subset of the geriatric population's knowledge and understanding of ACP and AD - thus potentially increasing the number of WV adult residents in other age groups who complete AD before a medical crisis occurs.

\section{Outcome Evaluation Plan}

The project's primary goal was for $50 \mathrm{WV}$ geriatric residents to complete AD after viewing a five- minute video decision aid and participating in verbal discussion in the outpatient clinical setting. Three process objectives were evaluated to support the primary goal. A data collection tool was utilized to track patient demographics and total number of AD forms completed after the project interventions. Using the IBM SPSS data analysis program, both quantitative and qualitative data was explored to measure the impact of the interventions and participant outcome as it relates to completion of $\mathrm{AD}$ documents.

The first process objective of increasing the number of $\mathrm{AD}$ document completion in the PCMH where the project was led underwent a statistical evaluation of the variables of verbal description (with and without video) and completion of AD. Per CMS criteria for health maintenance and preventive services, ACP discussion should occur as frequently as discussions that promote screenings and immunizations at the MWV. However, this has not been the case at the clinic where the project was led. Because of that, it was important to determine if any ACP intervention impacted patient's determination of EOL goals of care and completion of any AD document or medical order (MPOA, LW, POST).

The second process objective evaluated the intervention of an evidence-based video decision support aid in ACP counseling. The hypothesis is that integrating a multimodal approach of video and verbal interventions of ACP will influence patients to complete AD. To evaluate this objective, data was analyzed to quantify the impact of the video intervention. 
Running Head: A VIDEO DECISION AID TO INFLUENCE ADVANCE CARE PLANNING

Research finds significant evidence to support a video decision aid to enhance a patient's and provider's subjective and objective knowledge regarding EOL preparation (El-Jawahri et al., 2015). Through video use, content of ACP and EOL treatment options can be simplified for patient's understanding. When patients exemplify comprehension of the concept, only then can they make informed decisions of EOL care that aligns with their preferences and values. Moreover, the video intervention mitigates time constraints in the primary care setting necessary to effectively engage patients in ACP counseling.

The third process objective sought to align key principles from the evidence-based conversation and interview templates to best practice standards of the organization for the geriatric population. The APRN investigator used the principles from the Respecting Choices ${ }^{\circledR}$ 3-Steps framework (2017) to steer the verbal description component of the intervention. The actual templates are the intellectual property of the Respecting Choices ${ }^{\circledR}$ program therefor could not be copied or disseminated for reference. Because the APRN completed the program's facilitator certification course, using the templates were encouraged in ACP conversations. The key principles were included in a script designed by the APRN and made available in a designated ACP binder at the clinical practice setting where the project was led. This approach was a change in the current practice standard as previous patient-provider ACP counseling in the outpatient setting has historically been a brief and fleeting overview of AD documents. In most cases, these conversations are cursorily performed in the emergency department or acute care setting amidst a medical crisis. Attentive, focused engagement of patients and families is essential for informed, shared decision-making. The expectation of an evidence-based approach to ACP counseling in the PCMH is that it is an ongoing, dialogue that is scientifically sound and methodically elicits patient preferences and wishes. 
Running Head: A VIDEO DECISION AID TO INFLUENCE ADVANCE CARE PLANNING

\section{Results}

The analysis of the quantitative and qualitative data revealed interesting information about the impact of a video decision aid on influencing completion of AD. Further information regarding the intervention and control data are described in this section. In addition, the final outcomes reported by objective evaluations will be discussed.

\section{Impact of the Intervention}

Process Objective 1. This objective aimed to increase the number of AD completed by the geriatric population within the PCMH. To determine the outcome of this objective, a frequency and proportion distribution was generated to evaluate the output of the variables "any intervention" and "completion of AD". "Any intervention' entailed either the verbal description and video or verbal description only. The results showed 31 advance directive documents were completed from participants in both groups who received "any intervention" including one (1.9\%) POST for medical orders. In total, $73.8 \%$ of participants completed AD (See Table 2). It could not be determined if this was an actual increase for this clinic as no baseline data for the number of $\mathrm{AD}$ completion prior to the study were available. However, the completion rate demonstrates the need for ACP interactions to become a standard quality measure in a patient's continuum of care. It can be concluded that if this study were not undertaken in this PCMH, the frequency of ACP interactions with AD completion would be considerably fewer. This assumption is based from the low incidence rate of ACP interactions traditionally occurring within this practice setting.

Process Objective 2. This objective integrated an evidence-based video decision aid within patient-provider conversations for the purpose of strengthening ACP interactions. It was important to determine the association between the intervention or control group and completion 
Running Head: A VIDEO DECISION AID TO INFLUENCE ADVANCE CARE PLANNING

of AD. Because of the small sample size, a Fisher's Exact test was performed that showed a non-significant association $(p=.056)$ between the intervention and control groups. Although, these results were not statistically significant, $88 \%$ of the intervention group completed AD compared to $63 \%$ of the control group (See Table 3). These findings are similar to other national studies showing moderate quality evidence supporting a benefit of video use with results in greater ACP knowledge (Jain, et. al., 2014).

Process Objective 3. This objective sought to align evidenced-based guidelines for ACP conversations to the healthcare organization's best practice standards for the geriatric population. It was important to determine if using the evidence- based conversation templates designed by Respecting Choices ${ }^{\circledR}$ impacted the completion of AD. Because the project was recently completed, the objective was unable to be measured. Therefore, it cannot be concluded if the conversation templates have become a standard. Nevertheless, use of these evidencedbased guidelines offer a structured method to ACP discussion and should be used to align with best practice standards for the geriatric population and organization's mission and vision of a "patient centered system of care" by development of new approaches to improve healthcare (WVU Medicine, 2019).

\section{Discussion and Recommendations}

\section{Dissemination}

The findings of the research were anonymously collected and will be aggregated and shared at the DNP capstone presentation within the WVU School of Nursing. The findings may also be shared through publication in medical/nursing journals and poster presentations.

\section{Challenges and Limitations}


Running Head: A VIDEO DECISION AID TO INFLUENCE ADVANCE CARE PLANNING

Challenges. Although the intervention goals and project objectives were met and positive statistical data and narrative evidence were revealed, there were challenges encountered throughout the study implementation and will be discussed in this section.

Barriers to recruitment. The patient's refusal for participation was viewed as a barrier for attaining a larger sample size that potentially would have enhanced the quantitative and qualitative data results. However, these obstacles offered rich data that can be used to design future research studies that seek to expound these issues as they relate to a patient's understanding, beliefs, and possibly fear of EOL. It was considered that some patients may have been reluctant to discuss a sensitive topic, such as EOL preparation, with the APRN if she was not their primary care provider (PCP). Research has shown that most patients prefer their primary healthcare provider to initiate ACP counseling (Schlegal \& Shannon, 2000). Additionally, the no-show and cancellations of potential participants contributed to enrollment difficulties. The average expected "no-show" and cancellation rate of MWV appointments in this clinical setting is approximately $9 \%$ yearly. The APRN investigator was aware of this problem and attempted to offset that rate by mailing out consents to 70 patients theorizing that if $10 \%$ of those patients cancelled, 63 patients would attend their MWV, consequently providing an adequate sample size for this study.

Proper Documentation. Another challenge identified during the project was improper or incomplete documentation in the EMR regarding completed AD. Some patients considered for study participation already had completed AD without copies filed in their EMR. These patients noted that they were never asked if they had completed AD prior to this instance, although most had previously received a MWV where the standard assessment tool specifically asks if the patient had completed AD. In all the cases of those identified as a potential participant using the 
Running Head: A VIDEO DECISION AID TO INFLUENCE ADVANCE CARE PLANNING inclusion criteria of "not having completed AD" the answer "no" was documented in their EMR from previous MWV assessments. Additionally, these patients were not aware that they should provide their medical provider a copy of completed AD, elucidating that the topic of ACP and $\mathrm{AD}$ had not been broached with these patients in this clinical setting.

Limitations. There were limitations identified throughout the project that should be considered before implementing future research in other clinical settings, predominantly communication barriers and small sample size. During the study implementation it was determined that the APRN overlooked the provision for educational ACP materials and AD available in other languages. The video decision aid was chosen in part due to its availability in multiple foreign languages. There were Spanish speaking only patients participating in this study. These patients were able to view the video in their native language; however, AD documents were provided in English. Despite the language barrier, successful ACP was performed with the assistance of a family member translator. Spanish language ACP educational materials and AD documents have since been attained by the WVCEOLC and Five Wishes ${ }^{\circledR}$ program and provided to the Hispanic study participants with additional blank copies added to the ACP file in the clinical office. ACP educational materials and $\mathrm{AD}$ documents available in multiple languages should be a standard in all clinical practice settings given the multi-cultural patient population within this geographical region.

A second communication barrier that proved a hindrance to participation were the sensory deficits of some patients. Several patients were unable to view the video decision aid due to difficulty with vision or hearing. Although these are normal age- related changes in the elderly population, the communication difficulties that arise place challenges on the patient to take an active part in ACP and fully grasp the concept of the discussion. Because of that, 
Running Head: A VIDEO DECISION AID TO INFLUENCE ADVANCE CARE PLANNING clinicians are tasked with engaging elderly patients with sensory deficits in effective dialogue from which they can actively participate and clearly articulate EOL treatment preferences. Offering AD documents in larger print or providing a magnifying glass when reviewing the documents may mitigate some of the challenge, however, the use of a video decision aid in these situations is not a practical mode of communication.

Another limitation of this study was its small sample size. During the project's planning phase, 70 patients were identified as potential participants and thus sent a consent. Of those identified, 54 individuals attended the MWV, whereby 42 patients agreed to participate. Twelve other patients updated or completed $\mathrm{AD}$ as a result of knowing of the study but chose not to participate. Although the sample size of 54 targeted cases was determined adequate to offer statistical and clinical significance using the Joint Commission criteria, a larger sample would have provided a greater statistical power and generalizability of results for this subset population. Nevertheless, this study provided useful quantitative and qualitative information about the clinical benefit of a video decision aid for ACP interactions with patients and families.

\section{Recommendations}

\section{Project's Clinical Site}

This pilot project offered insight into the practicality of implementing a five-minute video decision aid within an outpatient clinical setting. With the guidance of Lewin's Change Management Theory model, a better understanding of the key factors that influence a sustained practice change was identified. This project revealed potential for further investigation into a quality improvement practice that aligns with the organization's mission "to improve the health status of WV residents by providing health and wellness services and expanding access to care". To move forward, it is recommended that this project be continued by clinicians who have a 
Running Head: A VIDEO DECISION AID TO INFLUENCE ADVANCE CARE PLANNING

vested interest in improving EOL care for the geriatric population. Because some participants did not bring a family member to their scheduled MWV appointment, it is recommended that follow up phone calls be made to patients one day prior so ACP conversations can include the potential MPOA and other family members involved with the EOL preparation. Also asking about existing AD during the follow up phone call is recommended so the documents can be made available in the EMR. Additionally, ACP interactions should be performed with younger individuals with life limiting illness as age does not deter the natural trajectory of advanced disease, hence the importance to prepare for EOL (Fletcher et al., 2017).

A longer duration study should be considered. A long- term experimental trial may show more relevant clinical measures of the influence of a video decision aid on the completion of AD in an outpatient practice setting. It is also recommended that a pre- post intervention study design be implemented. A measure of a patient's level of understanding of ACP when only counseling is performed (pre-intervention) compared to after viewing the video (post-intervention) would yield more clinically sound data regarding the value of the video intervention. Moreover, a larger sample size would be more representative of the population and offer a higher confidence in the validity and reliability of the video decision aid.

Successful integration of evidence-based guidelines using structured conversation and interview templates should be a standard tool in ACP counseling. It is necessary to evaluate their practicality and efficacy of use by the providers in the PCMH. Within an outpatient setting, there is no formal systematic or defined process to measure the utility of guidelines within practice. For this purpose, provider feedback is essential to inform statistical and qualitative data that determines if the evidence-based resources are being proportionately utilized and meets the intended overarching goal of more skillful ACP conversations. 
Running Head: A VIDEO DECISION AID TO INFLUENCE ADVANCE CARE PLANNING

The organization finds importance in the education of healthcare professionals and development of health care delivery strategies that includes team- based models of care and expansion of clinical and translational research. Because of that, it is recommended that the organization's leadership encourages clinical staff and providers to research and self-educate on health ethics and laws as they relate to EOL and ACP conversations. These conversations should be embedded into chronic care management and initiated earlier in a disease process. Current evidence suggests that discussion about prognosis and EOL care are uncommon and decisionmaking is poorly integrated into primary care, which leads many patients and families being ill prepared for the EOL (Obrador, 2018). To adhere to the organization's vision of a patient centered system of care, EOL conversations with elderly patients should be normalized by PCPs and occur intuitively and frequently as counseling for other preventive services. Lastly, educational materials on ACP and AD should be visible within the practice setting and routinely offered to patients and families, so they are better informed and aware that preparing for the EOL is an important step in their continuum of care.

\section{Implementation in Other Clinical Settings}

The evidence-based video decision aid demonstrated in this project is practical to implement in any clinical setting. The verbal description of ACP provided in this project enriched the standard dialogue. Both interventions demonstrated positive clinical benefit of the influence on ACP and AD completion. A best practice standard to ACP interactions is an ongoing communication between patient and provider. However, condensed but concise conversations occurring in busy practice settings can also lead to successful ACP intervention if the patient's values and preferences are identified. Obrador (2018) explains that high quality provider-patient conversation can increase the likelihood that health care organizations will make 
Running Head: A VIDEO DECISION AID TO INFLUENCE ADVANCE CARE PLANNING sense and learn in ways that enable them to achieve their goals and to serve their patients in positive ways. The video download was free of charge and can be accessed from any computer or iPad in multiple clinical settings making this a versatile tool. The video can be initiated by all levels of office and clinical staff. The video content was a five-minute brief, succinct overview of ACP and the importance of completing AD documents. The content was simple and easy to understand so that patients of varying educational levels could comprehend. Billing for ACP is done under the preventive service for CMS beneficiaries and although limitless ACP interactions can be billed for each beneficiary, this type of service is usually only provided in the acute care or PCMH rather than a specialty practice.

\section{Future Research}

Recommendations for future research is based on information gleaned from the literature synthesis and project outcomes and will be discussed in this section. Implementing ACP education for healthcare providers may facilitate more frequent EOL discussion that lends to an increased number of elderly patients completing AD. The literature review and project findings provide clear evidence that video decision aids are often an effective and valuable visual aid in ACP. When information is conveyed in a multimodal approach, a patient's level of knowledge improves, facilitating self -determination and shared decision-making for EOL treatment preferences. Gaps identified in the literature review offer a basis for which future research may be warranted. None of the studies reviewed the patient's confidence level on EOL decision-making after viewing the video. A pre-post study design investigating a patient's level of understanding of ACP concepts before and after video viewing should be considered. Although several studies confirmed the positive impact that APRNs have on ACP, it was noted that APRNs possess limited knowledge on the regulatory and legal aspects of ACP. More 
Running Head: A VIDEO DECISION AID TO INFLUENCE ADVANCE CARE PLANNING

research should be done to further investigate how education on legal guidelines would influence outcomes after APRN led ACP counseling. In addition, organizational culture as well as health care regulation was shown to highly influence APRNs initiating ACP with patients in certain health care settings. APRNs working in acute care settings more often engage patients in ACP than APRNs in an outpatient setting (Reitze et al., 2016). Further investigation would benefit in determining how organizational culture and regulation shapes healthcare provider's perception of ACP in various clinical practice settings. Because of these disparities in the literature, more comprehensive research is needed to investigate the factors that would bestow a stronger evidenced-based approach to the ACP process that is patient centered, family oriented, and shapes health care provider's efforts to improve patient outcomes

\section{Attainment of DNP Essentials}

The DNP Essentials gave context and soundness to this study project. Criteria was met to attain the eight essentials throughout the course of the project as delineated below.

Essential I: Scientific Underpinnings for Practice. This essential was met by utilizing the Change Theory model as the theoretical framework to guide this project and delineate recommendations for a clinical practice change. A systematic review was performed to demonstrate validity and rationale for the intervention of the video decision aid and provided a scientific basis for this project.

\section{Essential II: Organizational and Systems Leadership for Quality Improvement and}

Systems Thinking. This essential was met by investigating the utility of a video decision aid as an integrated communication modality to the ACP process. This effective mode of communication is practical and can be easily integrated within the organization's established systems to improve the quality of the ACP process. 
Running Head: A VIDEO DECISION AID TO INFLUENCE ADVANCE CARE PLANNING

Essential III: Clinical Scholarship and Analytical Methods for Evidence-Based Practice.

This essential was met by utilizing a systematic review process which found evidence in favor of the use of video education in ACP, thus support for a clinical practice change and design of this project.

\section{Essential IV: Information Systems/Technology and Patient Care Technology for the}

Improvement and Transformation of Health Care. This essential was met by collaborating with the organization's IT department to ensure all providers are informed of the integrated EMR program feature which prompts clinical staff and providers of patient's ACP status. Also, employing the video decision aid by using an iPad and instructing patients and family members on how to operate the device and how to access the video on their personal devices. This video can be easily accessed from patient's computers or iPads, therefor affording the capability to review the video content and similar videos at home.

Essential V: Health Care Policy for Advocacy in Health Care. This essential was attained by demonstrating within the clinical setting the positive outcome of a multimodal approach to ACP with the use of a video decision aid and advocating for organizational policy change that standardizes evidenced-based and legal guidelines within the framework of performance improvement.

\section{Essential VI: Interprofessional Collaboration for Improving Patient and Population Health}

Outcomes. This essential was met by working collaboratively with the organization's administration, staff, providers, and WVU faculty to successfully implement this project. The interprofessional collaboration facilitated a potential practice change that offers an evidencebased structure to the ACP process, thus improving patient outcomes and consequently an overall benefit to the elderly population of $\mathrm{WV}$. 
Running Head: A VIDEO DECISION AID TO INFLUENCE ADVANCE CARE PLANNING

Essential VII: Clinical Prevention and Population Health for Improving the Nation's

Health. This essential was met by evaluating the effectiveness of the video intervention as part of a clinical practice change. A call for state-wide providers, namely APRNs, to self -educate on the clinical and legal structure of the ACP process in various clinical settings and developing a resource manual that includes evidence-based guidelines meets criteria for attainment of this essential.

Essential VIII: Advanced Nursing Practice. This essential was attained by the design, implementation, evaluation, and dissemination of study results. All input and output efforts of this project lends to the attainment of the eight DNP essentials, which offers the foundation for advanced practice nursing on a doctoral level. 
Running Head: A VIDEO DECISION AID TO INFLUENCE ADVANCE CARE PLANNING

\section{References}

Advance Care Planning Decisions. (n.d). Retrieved from https://acpdecisions.org/

CDC (n.d). Advance care planning evidenced-based resources. Retrieved from https://www.cdc.gov/training/ACP/Resources.pdf

CDC Healthy Aging. (n.d). Advance care planning: ensuring your wishes are known and honored if you are unable to speak for yourself. Retrieved from https://www.cdc.gov/aging/pdf/advanced-care-planning-critical-issue-brief.pdf

Center for Medicare and Medicaid Services. (2018). Retrieved from https://www.cms.gov/outreach-and-education/medicare-learning-network$\underline{\text { mln/mlAPRNroducts/downloads/advancecareplanning.pdf }}$

Constantine, L.A., Dichiacchio, T., Falkenstine, E.C., \& Moss. A.H. (2018). Nurse Practitioner completion of physician orders for scope of treatment forms in West Virginia: A secondary analysis of 12 months of data from the state registry. Journal of American Association of Nurse Practitioners, 30(1). 10 - 16

Dube, M., McCarron, A., \& Nannini, A. (2015). Advance care planning complexities for nurse practitioners. Journal for Nurse Practitioners. 11(8). 766-773

El- Jawahri, A., Paasche-Orlow, M.K., Matlock, D., Stevenson, L.W., Lewis, E. F., Stewart, G., Semigran, M., Yuchiao, C., Parks, K., Walker-Corkery, E. S., Temel, J.S., Bohossian, H., Ooi, H., Mann, E., Volandes, A.E. (2016).

Randomized, controlled trial of an advance care planning video decision support tool for patients with advanced heart failure. Circulation. doi:

10.1161/CIRCULATIONAHA.116.021937

Fletcher, S., Hughes, R., Pickstock, S., \& Auret, K. (2017). Advance care planning discussions 
Running Head: A VIDEO DECISION AID TO INFLUENCE ADVANCE CARE PLANNING with adolescent and young adult cancer patients admitted to a community palliative care Service: A retrospective case-note audit. J Adolescent Young Adult Oncology. 7(1), 112119. doi: 10.1089/jayao.2017.0032.

Institute of Medicine. (2014). Dying in America, improving quality and individual preferences at the end-of-life. Institute of Medicine. Retrieved from http://www.nationalacademies.org/hmd/ /media/Files/Report\%20Files/2014/EOL/Report \%20Brief.pdf

Jain, A., Corriveau, S., Quinn, K., Gardhouse, A., Begas, D.B., \& You, J.J. (2014). Video decision aids to assist with advance care planning: a systematic review and meta-analysis. BMJ Open. doi: 10.1136/bmjopen-2014-007491

Kaminski, J. (2011). Theory applied to informatics-Lewin's change theory. Canadian Journal for Nursing Informatics. Retrieved from http://cjni.net/Journal_original/Winter2011/cjni.net_Theory_applied_to_informatics_\%96_Lewin\%92s_Change_Theory__CJNI_Journal_. pdf

Kates, J. (2017). Advance care planning conversations. The Journal for Nurse Practitioners. Retrieved from http://dx.doi.org/10.1016/j.nurpra.2017.05.011

Kermel-Schiffman, I. \& Werner, P. (2017). Knowledge regarding advance care planning: A systematic review. Archives of Gerontology and Geriatrics. 73, 133-142. doi: 10.1016/j.archger.2017.07.012

Larrabee, J.H. (2009) Nurse to nurse evidenced-based practice: Expert interventions. 54 - 55 Lounsbery, K. (2019). Healthcare's primary decision maker is female. NRC Health. Retrieved from https://nrchealth.com/editorial-healthcares-primary-decision-maker-female/ 
Running Head: A VIDEO DECISION AID TO INFLUENCE ADVANCE CARE PLANNING

National Hospice and Palliative Care Organization. (2017). Advance care planning. Retrieved from https://www.nhpco.org/advance-care-planning

Obrador, Gregoria T. (2018). The provider's role in conservative care and advance care planning in patients with ESRD. Clinical Journal of American Society of Nephrology. Retrieved from https://www.ncbi.nlm.nih.gov/pmc/articles/PMC4858476/

Rao, J.K., Anderson, L.A., Feng-Chang, L, \& Laux, J.P. (2014). Completion of advance directives among U.S. consumers. American Journal of Preventive Medicine. 46(1), 6570. doi: 10.1016/j.amepre.2013.09.008

Respecting Choices, 2017. Gunderson Medical Foundation. Retrieved from https://respectingchoices.org/

Rietze, L., Heale, R., Hill, L., \& Roles, S. (2016). Advance care planning in nurse practitioner Practice: A cross-sectional descriptive study. Nursing Leadership. Retrieved from https://www.researchgate.net/publication/312050184_Advance_Care_Planning_in_Nurse _Practitioner_Practice_A_Cross-Sectional_Descriptive_Study

Schlegel, K.L., Shannon, S.E. (2000). Legal guidelines related to end-of-life decision; are nurse practitioners knowledgeable? Journal of Gerontological Nursing. 26(9), 14-24

Splendore, E. \& Grant, C. (2017). A nurse practitioner-led community workshop: increasing adult participation in advance care planning. Journal of American Association of Nurse Practitioners. doi: 10.1002/2327-6924.12467

U.S. Department of Health and Human Services Assistant Secretary for Planning and Evaluation Office of Disability, Aging and Long-Term Care Policy. (2008). Advance directive and advance care planning: Report to Congress. Retrieved from https://aspe.hhs.gov/system/files/pdf/75811/ADCongRpt.pdf 
Running Head: A VIDEO DECISION AID TO INFLUENCE ADVANCE CARE PLANNING

VitalTalk.org. (n.d.). Retrieved from https://www.vitaltalk.org/resources/

Volandes, A.E., Passche-Oslow, M.K., Davis, A.D., Eubanks, R., El-Jawhri, \& Seitz, R. (2016). Use of video decisions aids to promote advance care planning. General Internal Medicine. 31(9), 1035- 1040

Weathers, E., O’Caoimh, R., Cornally, N., Fitzgerald, C., Kearns, T., Coffey, A. Daly, E., O’Sullivan, R., \& McGlade, C. (2016). Advance care planning: A systematic review of randomized controlled trials conducted with older adults. Elsevier. Retrieved from http://dx.doi.org/10.1016/j.maturitas.2016.06.016

West Virginia Center for End of Life Network. (2019). Retrieved from www.wvendoflife.org

West Virginia Rural Health Association (2013). Health care in West Virginia: A workforce demand analysis. Retrieved from file:///F:/west-virginia-workforce-demand-report-10_9final-11-pm.pdf

White, N., Kupeli, N., Vickerstaff, V., \& Stone, P. (2017). How accurate is the "surprise question" at identifying patients at the end-of-life? A systematic review and metaanalysis. BMC Medicine. doi: 10.1186/s12916-017-0907-4 
Figure 1

Kurt Lewin's Three-Step Change Model

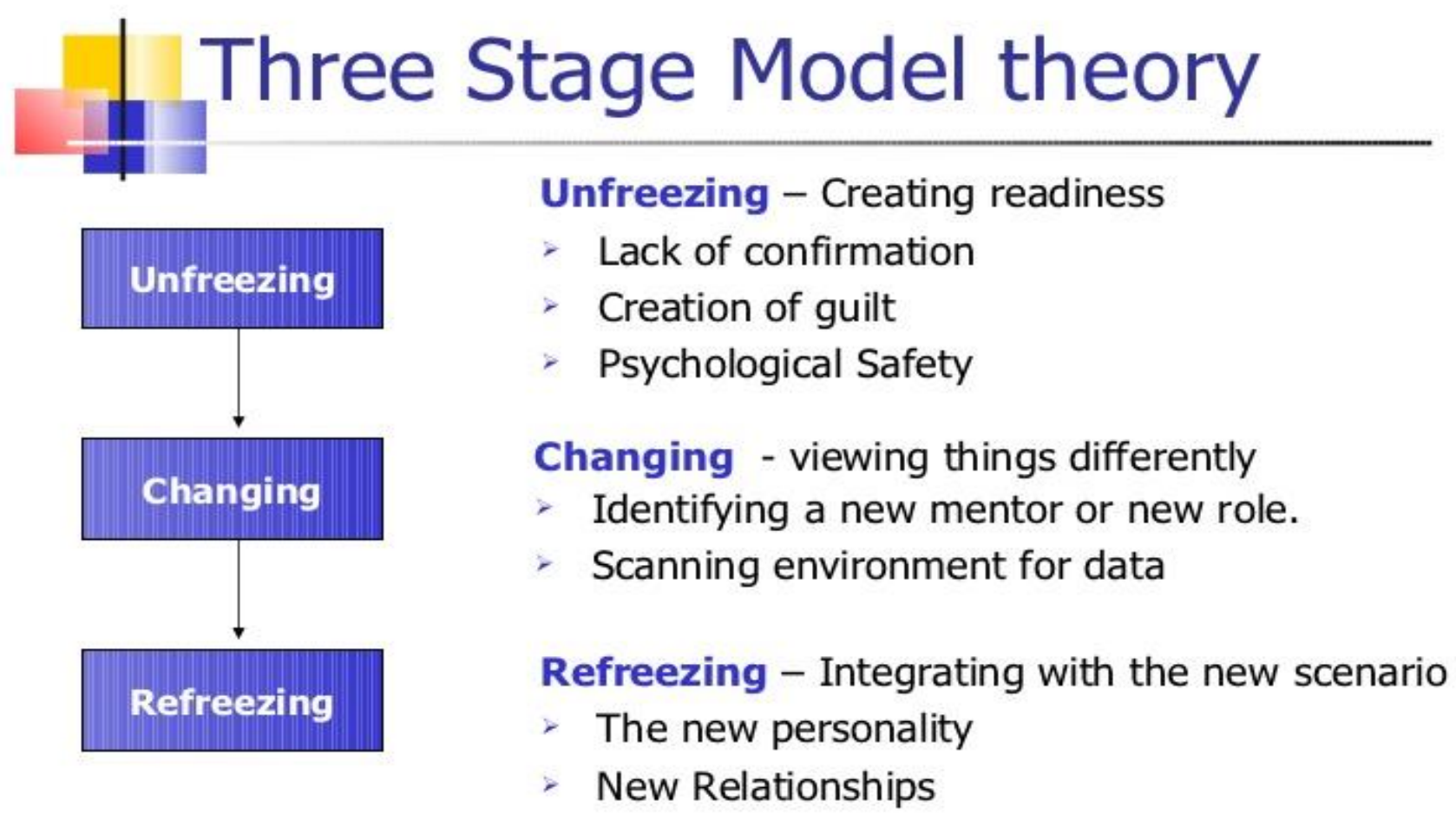


Running Head: A VIDEO DECISION AID TO INFLUENCE ADVANCE CARE PLANNING

Figure 2

Kurt Lewin's Force Field Analysis Model

Integration of Force Field Analysis \& Reinforcement Theory

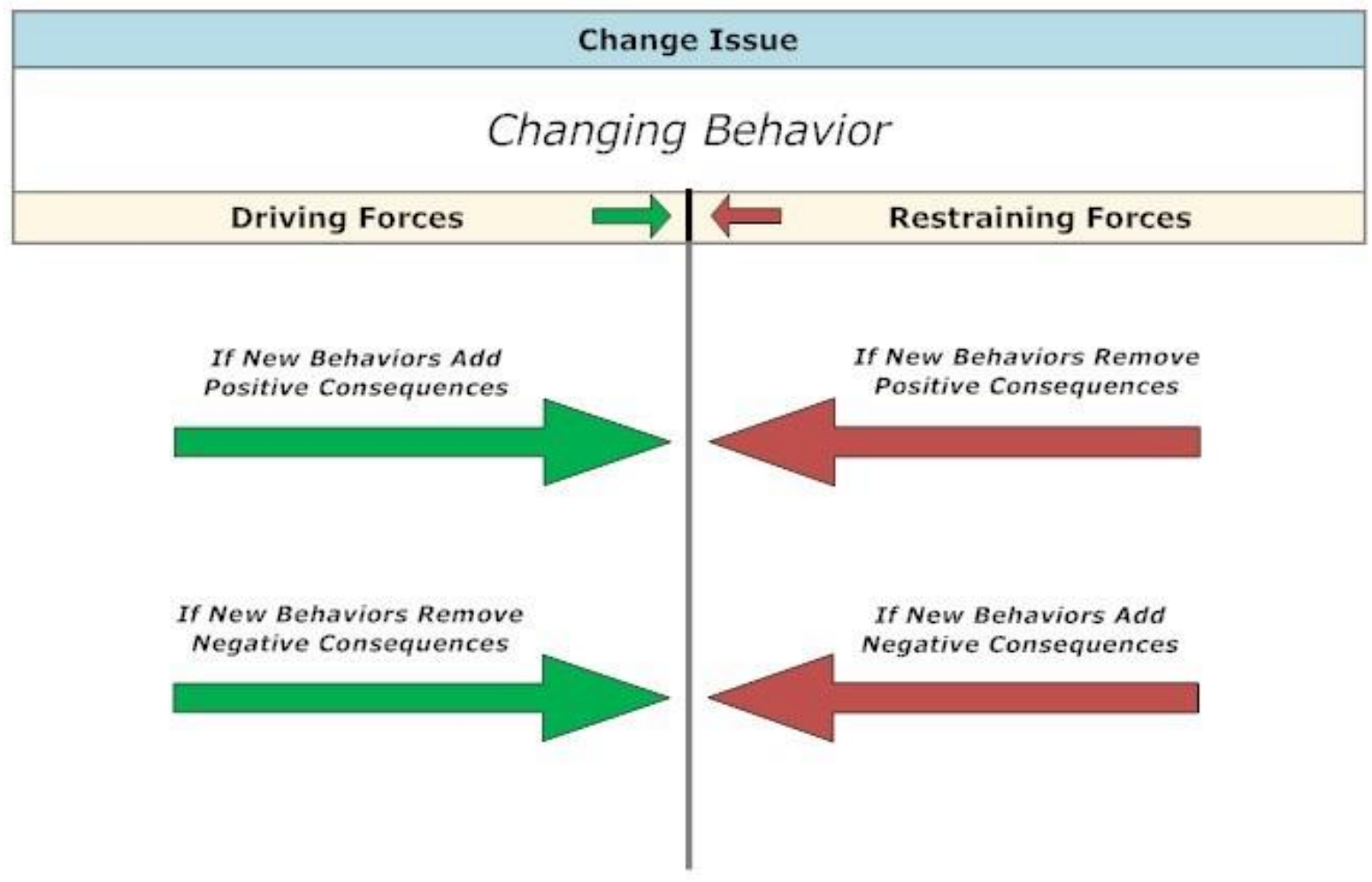


Running Head: A VIDEO DECISION AID TO INFLUENCE ADVANCE CARE PLANNING

Figure 3

Letter of Permission

\section{Letter of Permission to Conduct Research}

I, Dr. George Harris. UHP Medical Director, give my permission for Angela Petry and Dr. Lori Constantine to conduct the study entitled A Video Decision Support Tool for Advance Care Planning at Ranson Family Medicine and Jefferson Medical Center.

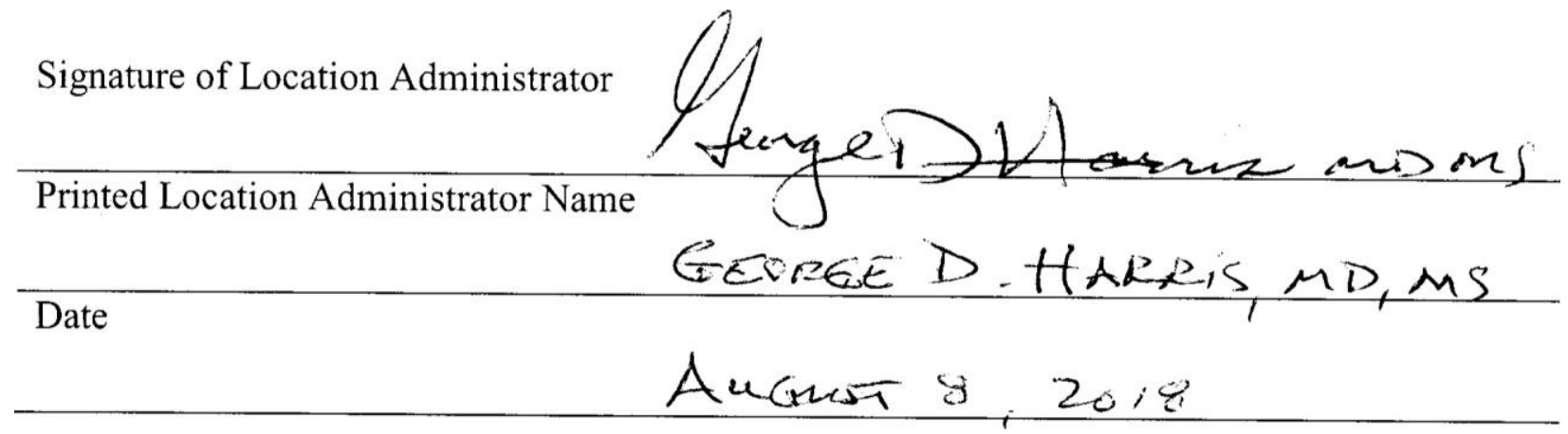


Running Head: A VIDEO DECISION AID TO INFLUENCE ADVANCE CARE PLANNING

\section{Appendix A}

\section{Conversation Template/Interview Tool for Advance Care Planning}

The principles outlined in this document are derived from Respecting Choices ${ }^{\circledR}$ evidenced based guidelines and have been demonstrated as a valid and reliable approach to advance care planning discussion with patients of various health status and their families.

1. Assess the motivation, knowledge, and beliefs of the individual.

Ex. "Hello. Today were going to discuss advance care planning and importance in making decisions for your future health if a serious illness or injury were to occur. This often takes more time than people expect, but we can begin today and continue the conversation at your next appointment if you wish. I will start with asking a question.

"What do you understand about advance care planning and advance directives (AD)?"

For individuals who have completed an advance directive:

"Tell me what type of document you have created?"

"Have you chosen a person who would make decisions for you?

What conversations, if any, have you had with this person?"

"What do you hope this document will do for you in the future?"

"This conversation may help you update your plan".

2. Provide clarification on ACP or AD as needed.

Ex. "Advance Care planning is for all adults. It helps you to begin thinking and talking about future healthcare decisions if you suddenly fell seriously ill or injured, like stroke, heart attack, or vehicle accident- and not able to make your own decisions. A person close to you would need to make these decisions, this is your healthcare agent. This conversation will help you and your agent understand your treatments goals and values. These will also help your agent make the right decision for you"

"Do you need any further clarification on these ideas concepts?"

"What fears or concerns do you have about advance care planning?"

\section{Assess understanding of the role of healthcare agent.}

Ex: "I'd like to review for important qualities of a healthcare agent". 
Running Head: A VIDEO DECISION AID TO INFLUENCE ADVANCE CARE PLANNING

\section{Appendix B}

Data Collection Tool

\begin{tabular}{|c|c|c|c|c|c|c|c|c|c|}
\hline Age & $\begin{array}{l}\text { Gender/ } \\
\text { Capacity }\end{array}$ & $\mathrm{Ed}$ & Group: I/C & $\begin{array}{l}\text { Discussion } \\
\text { per } \\
\text { Standard of } \\
\text { care }\end{array}$ & $\begin{array}{l}\text { Type of AD } \\
\text { Completed }\end{array}$ & $\begin{array}{l}\text { County of } \\
\text { residence }\end{array}$ & $\begin{array}{l}\text { Visit } \\
\text { type }\end{array}$ & $\begin{array}{c}\text { Family } \\
\text { viewed } \\
\text { video }\end{array}$ & Code \\
\hline & & & & & & & & & \\
\hline & & & & & & & & & \\
\hline & & & & & & & & & \\
\hline & & & & & & & & & \\
\hline & & & & & & & & & \\
\hline & & & & & & & & & \\
\hline & & & & & & & & & \\
\hline & & & & & & & & & \\
\hline & & & & & & & & & \\
\hline & & & & & & & & & \\
\hline & & & & & & & & & \\
\hline & & & & & & & & & \\
\hline & & & & & & & & & \\
\hline & & & & & & & & & \\
\hline & & & & & & & & & \\
\hline & & & & & & & & & \\
\hline & & & & & & & & & \\
\hline
\end{tabular}


Running Head: A VIDEO DECISION AID TO INFLUENCE ADVANCE CARE PLANNING

\section{Appendix C}

DNP Project Budget

\begin{tabular}{|l|l|l|}
\hline Budget Categories & Personal Fund & $\begin{array}{l}\text { Organizational } \\
\text { Contributions }\end{array}$ \\
\hline Administrative Costs & $\$ 0$ & $\$ 187.50$ \\
\hline Adming
\end{tabular}

Administrative justification: Over the course of the study, the total time needed by the Medical Assistant (MA) will be approximately 12.5 hours. The average effort estimate cost of an MA is $\$ 15.00 /$ hour $\mathrm{x} 12.5$ hours $=$ $\$ 187.50$. This time will be utilized to prepare the video for viewing by the patient, assisting with EMR updates of Advance Directives, scanning documents into the EMR, and faxing documents to the e-Registry. The staff will also see patients in their usual care clinic visits. No staff time will be needed outside of usual business hours.

\begin{tabular}{|l|l|l|}
\hline Marketing & $\$ 0$ & $\$ 0$ \\
\hline Marketing justification: N/A & $\$ 49$ & $\$ 0$ \\
\hline Educational Materials & & \\
\hline
\end{tabular}

Educational materials are provided free from the ACPdecisions.org and West Virginia end-of-life Network website. These include a "Fast Facts" handout, the Advance Care Planning video (English and Spanish version), AD documents, POLST forms, and DNR cards. These forms will be sent directly to me at the cost of the WV EOL network. Personal cost (\$49.00) includes the ACP webinar that I will be viewing to enhance my knowledge base of ACP counseling.

\begin{tabular}{|l|l|l|}
\hline Hospitality (food, room, rentals, ect.) & $\$ 50$ & $\$ 0$
\end{tabular}

Hospitality justification: A 30 -minute staff meeting during lunch will be necessary to educate the office staff of the planned project, expectations, tasks, workflow, ect. The cost entails lunch provided by me for that meeting. \begin{tabular}{|l|l|l|}
\hline Project Supplies & $\$ 574$ & $\$ 94.75$
\end{tabular}

Organization justification: Laptop or IPAP, paper, stamps, and envelopes. These materials are already utilized by the organization when sending letters to notify the patients of their scheduled Annual Wellness Exam. A laptop or IPad will be borrowed from existing resources in my office. This project will incur no additional cost to the organization.

Personal cost includes printer paper, pens, and Advance Directive forms

\begin{tabular}{|l|l|l|}
\hline Travel Expense & $\$ 0$ & $\$ 0$ \\
\hline & $(\$ 673.00)$ & $(\$ 282.25)$ \\
\hline Total Expense & $\$ 4050.00$ \\
\hline Cost Benefit & $\begin{array}{l}\text { Cost benefit justification: The organization received an income from the documentation and billing of ACP } \\
\text { interactions using established CPT billing codes }\end{array}$ \\
\hline Total Cost & $\mathbf{( \$ 6 7 3 . 0 0 )}$ & $\mathbf{\$ 3 7 6 7 . 7 5}$ \\
\hline
\end{tabular}


Running Head: A VIDEO DECISION AID TO INFLUENCE ADVANCE CARE PLANNING

\section{Appendix D}

Organization Mission and Values Linked to the Projects' Goals and Objectives

\begin{tabular}{|c|c|}
\hline \multicolumn{2}{|c|}{$\begin{array}{c}\text { Project Goal: } 50 \text { WV residents > } 55 \text { years of age will complete Advance Directives by March } \\
\text { 2019, after viewing a } 5 \text {-minute video support tool on Advance Care Planning options at their } \\
\text { annual Medicare Wellness Visit. }\end{array}$} \\
\hline Organization's Mission and Values & Project Objectives \\
\hline $\begin{array}{l}\text { Mission } \\
\text { To improve the health status of Eastern } \\
\text { Panhandle residents by providing excellence in } \\
\text { health and wellness services, expanding access } \\
\text { to care, and participating in the education of } \\
\text { healthcare professionals" }\end{array}$ & \\
\hline Vision & Objectives \\
\hline Patient centered system of care $\rightarrow$ & $\begin{array}{l}\text { Increase number of elderly patients in WV who } \\
\text { engage in ACP and complete AD in their } \\
\text { Primary Care Medical Home (PCMH) }\end{array}$ \\
\hline $\begin{array}{l}\text { Development of new approaches to improve } \\
\text { healthcare, including team-based models of } \\
\text { care, expanding WVU clinical and translational } \\
\text { research } \rightarrow\end{array}$ & $\begin{array}{l}\text { Utilize an evidence-based decision support tool } \\
\text { that will sustain practicality and validity by } \\
\text { enriching the clinician's counseling of ACP } \\
\text { and EOL issues. }\end{array}$ \\
\hline $\begin{array}{l}\text { A culture of performance and excellence } \\
\text { throughout the network } \rightarrow\end{array}$ & $\begin{array}{l}\text { Align best practice for the WV geriatric } \\
\text { population with current practice standards of } \\
\text { the health care organization }\end{array}$ \\
\hline
\end{tabular}


Running Head: A VIDEO DECISION AID TO INFLUENCE ADVANCE CARE PLANNING

\section{Appendix E}

Data Collection Plan

\begin{tabular}{|c|c|c|c|c|c|}
\hline Output/Outcomes & Measure/Indicator & Data Source & $\begin{array}{c}\text { Measurement } \\
\text { Interval }\end{array}$ & Target/Benchmark & Person Responsible \\
\hline $\begin{array}{l}\text { Outputs: } \\
\text { Patients will view a } 5 \text { - } \\
\text { minute video on ACP }\end{array}$ & $\begin{array}{l}\text { Each patient at their } \\
\text { scheduled MWV }\end{array}$ & $\begin{array}{l}\text { Online video at } \\
\text { ACPdecisions.org }\end{array}$ & $\begin{array}{l}\text { Every } 4 \text { to } 6 \text { weeks } \\
\text { starting December } \\
2018 \text { until March } 2019 .\end{array}$ & $\begin{array}{l}50 \text { patients by March } \\
2019 \text { will view the } \\
\text { video. }\end{array}$ & APRN will initiate the video \\
\hline
\end{tabular}


Running Head: A VIDEO DECISION AID TO INFLUENCE ADVANCE CARE PLANNING

\begin{tabular}{|c|c|c|c|c|c|}
\hline Outcomes: & & & & & \\
\hline $\begin{array}{l}\text { Clinician provides } \\
\text { informative ACP } \\
\text { communication } \\
\text { Patients will clearly } \\
\text { articulate EOL wishes }\end{array}$ & $\begin{array}{l}\text { Same as above } \\
\text { Patients will ask } \\
\text { appropriate questions } \\
\text { and state realistic } \\
\text { outcomes of EOL goals } \\
\text { of care }\end{array}$ & $\begin{array}{l}\text { Outlined in patient's } \\
\text { AD documents }\end{array}$ & Ongoing & $\begin{array}{l}\text { All patients engaged in } \\
\text { EOL communication } \\
\text { with provider and } \\
\text { family }\end{array}$ & $\begin{array}{l}\text { Clinicians will provide } \\
\text { educational and evidenced- } \\
\text { based counseling for patients } \\
\text { to make informed choices for } \\
\text { EOL goals of care }\end{array}$ \\
\hline $\begin{array}{l}\text { Practitioners will } \\
\text { incorporate clinical and } \\
\text { legal guidelines of ACP } \\
\text { counseling }\end{array}$ & $\begin{array}{l}\text { Evidenced by accurate } \\
\text { completion of } \mathrm{AD}\end{array}$ & $\begin{array}{l}\text { Evidence-based } \\
\text { conversation templates } \\
\text { as listed above }\end{array}$ & Ongoing & $\begin{array}{l}\text { All clinicians who } \\
\text { provide ACP } \\
\text { counseling }\end{array}$ & $\begin{array}{l}\text { All clinicians who provide } \\
\text { ACP counseling }\end{array}$ \\
\hline $\begin{array}{l}50 \text { elderly WV residents } \\
\text { will complete } \mathrm{AD} \text { in the } \\
\mathrm{PCMH} \text { setting }\end{array}$ & $\begin{array}{l}\text { Number of AD } \\
\text { documents completed } \\
\text { by March } 2019\end{array}$ & $\begin{array}{l}\text { WV e-Directive } \\
\text { Registry }\end{array}$ & Yearly & $\begin{array}{l}\text { Within } 5 \text { to } 7 \text { years, } \\
75 \% \text { of WV elderly } \\
\text { adult residents will } \\
\text { complete AD }\end{array}$ & $\begin{array}{l}\text { Organization and health care } \\
\text { system wide effort }\end{array}$ \\
\hline
\end{tabular}


Running Head: VIDEO USE IN ADVANCE CARE PLANNING

\section{Appendix F}

DNP Project Timeline

\begin{tabular}{|c|c|c|c|c|c|c|c|c|}
\hline Goal & December & January & February & March & April & May & June & July \\
\hline $\begin{array}{l}\text { Begin project } \\
\text { implementation }\end{array}$ & $\mathbf{X}$ & & & & & & & \\
\hline $\begin{array}{l}\text { Revisions and } \\
\text { edits to } \\
\text { manuscript }\end{array}$ & & $\mathbf{X}$ & & & & & & \\
\hline $\begin{array}{l}\text { Complete } \\
\text { project data } \\
\text { collection }\end{array}$ & & & $\mathbf{X}$ & & & & & \\
\hline $\begin{array}{l}\text { Complete } \\
\text { Manuscript }\end{array}$ & & & & $\mathbf{X}$ & $\mathrm{X}$ & & & \\
\hline $\begin{array}{l}\text { Paper } \\
\text { submission to } \\
\text { chair }\end{array}$ & & & & & & $3 r d$ & & \\
\hline $\begin{array}{l}\text { Paper } \\
\text { submission to } \\
\text { committee }\end{array}$ & & & & & & 17 th & & \\
\hline $\begin{array}{l}\text { Final } \\
\text { Committee } \\
\text { Approval }\end{array}$ & & & & & & & $3 \mathrm{rd}$ & \\
\hline Oral defense & & & & & & & $\begin{array}{c}16^{\text {th }} \\
\text { or } \\
17 \text { th }\end{array}$ & \\
\hline Submit to EDT & & & & & & & & $\begin{array}{l}\text { By } 5 \mathrm{pm} \\
\text { on } 26 \mathrm{th}\end{array}$ \\
\hline
\end{tabular}


Running Head: VIDEO USE IN ADVANCE CARE PLANNING

Table 1

\section{Reasons for Participation Refusal}

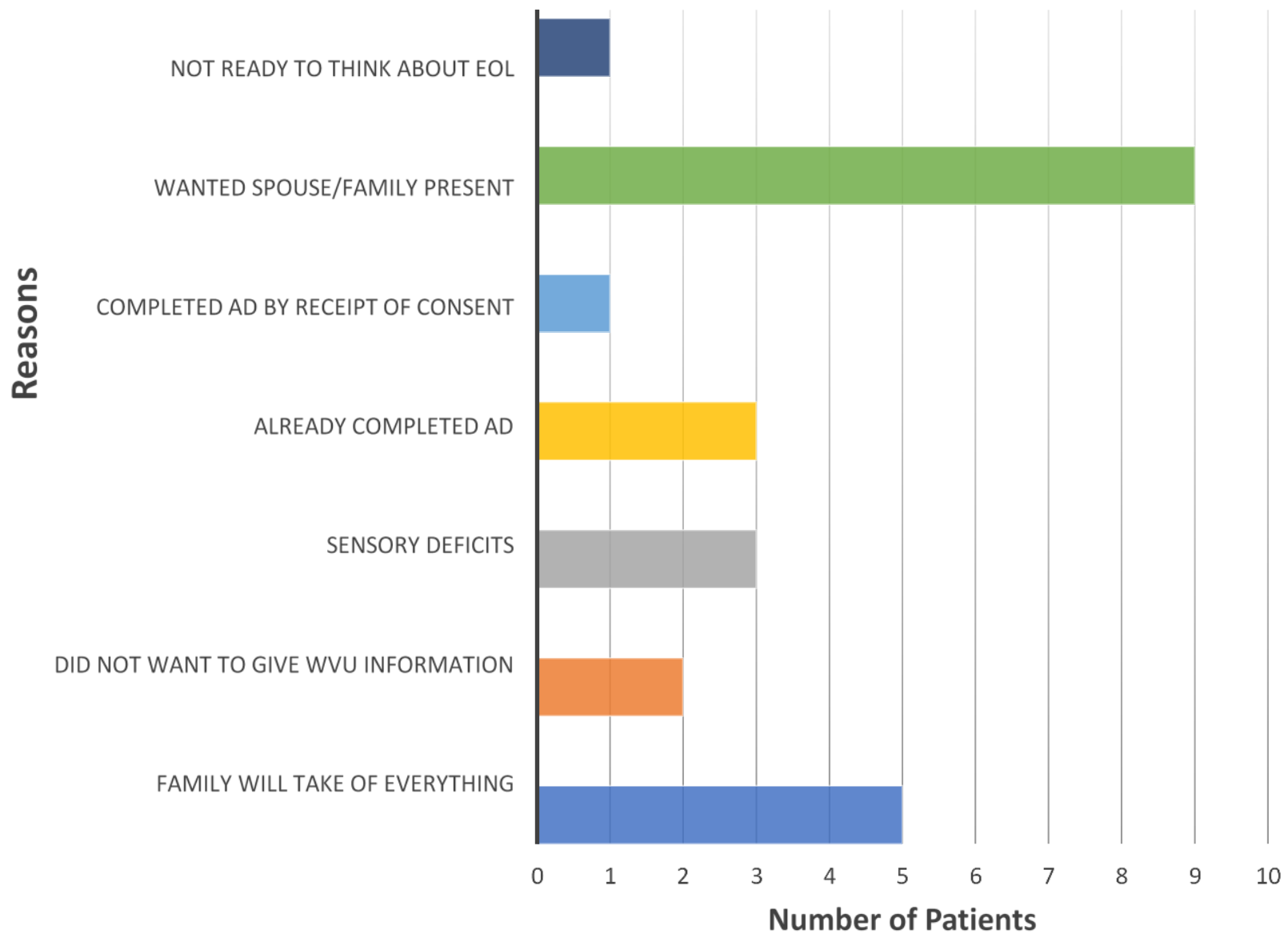

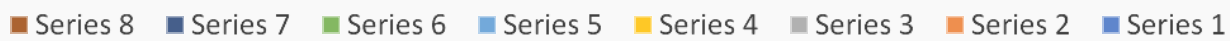


Running Head: A VIDEO DECISION AID TO INFLUENCE ADVANCE CARE PLANNING

Table 2

Advance Directive Completion by Any Intervention

\begin{tabular}{|l|l|l|l|}
\hline \multicolumn{1}{|c|}{ AD Completion } & \multicolumn{1}{c|}{ Frequency } & \multicolumn{1}{c|}{ Percent } & Valid Percent \\
\hline & & & \\
\hline Not Completed & 11 & $26.2 \%$ & $26.2 \%$ \\
\hline Completed & 31 & $73.8 \%$ & $73.8 \%$ \\
\hline Total & 42 & $100 \%$ & $100 \%$ \\
\hline
\end{tabular}


Running Head: A VIDEO DECISION AID TO INFLUENCE ADVANCE CARE PLANNING

Table 3

Advance Directive Completion by Intervention Type

\begin{tabular}{|c|c|c|c|}
\hline Intervention Type & Not Completed & Completed & Total \\
\hline Verbal Description Only & 9 & $15(63 \%)$ & 24 \\
\hline $\begin{array}{c}\text { Verbal Description PLUS } \\
\text { Video }\end{array}$ & 2 & $16(89 \%)$ & 18 \\
\hline Total & $11(26.1 \%)$ & $\mathbf{3 1}(\mathbf{7 3 . 8 \%})$ & 42 \\
\hline
\end{tabular}

